\title{
A Novel Approach to Enhance Mechanical and Thermal Properties of SLA 3D Printed Structure by Incorporation of Metal-Metal Oxide Nanoparticles
}

\author{
Suhail Mubarak ${ }^{1,2}$, Duraisami Dhamodharan ${ }^{1,2}{ }^{-}$, Manoj B. Kale ${ }^{1,2}{ }^{\oplus}$, Nidhin Divakaran ${ }^{1,2}$, \\ T. Senthil ${ }^{3}$, Sathiyanathan P. ${ }^{1}\left(\mathbb{D}\right.$, Lixin $\mathrm{Wu}^{1,4, *}$ and Jianlei Wang ${ }^{1, *}$ \\ 1 CAS Key Laboratory of Design and Assembly of Functional Nanostructure, and Fujian Key Laboratory of \\ Nanomaterials, Fujian Institute of Research on the Structure of Matter, Chinese Academy of Sciences, \\ Fuzhou 350002, China; suhail@fjirsm.ac.cn (S.M.); duraisamidhamodharan@fjirsm.ac.cn (D.D.); \\ manojkale@fjirsm.ac.cn (M.B.K.); nidhin@fjirsm.ac.cn (N.D.); sat.bni@gmail.com (S.P.) \\ 2 University of Chinese Academy of Sciences, Beijing 100049, China \\ 3 Advanced Research School for Technology and Product Simulation, Central Institute of Plastics Engineering \\ and Technology, Chennai 600032, India; tsenthilsci@gmail.com \\ 4 National Engineering Research Center for Optoelectronic Crystalline Materials, Fuzhou 350002, China \\ * Correspondence: lxwu@fjirsm.ac.cn (L.W.); jlwang@fjirsm.ac.cn (J.W.)
}

Received: 30 October 2019; Accepted: 23 January 2020; Published: 27 January 2020

\begin{abstract}
Silver (Ag) ornamented $\mathrm{TiO}_{2}$ semiconducting nanoparticles were synthesized through the sol-gel process to be utilized as nanofillers with photo resin to enhance the mechanical and thermal properties of stereolithography 3D printed objects. The as-prepared $\mathrm{Ag}^{-\mathrm{TiO}_{2}}$ nanoparticles (Ag-TNP) were typified and qualified by XRD, XPS, Raman, and FESEM; TEM analysis dissected the morphologies. The enhancement in the tensile and flexural strengths of SLR/Ag-TNP nanocomposites was noted as $60.8 \%$ and $71.8 \%$, respectively, at the loading content of $1.0 \% w / w$ Ag-TNP within the SLR (stereolithography resin) matrix. Similarly, the thermal conductivity and thermal stability were observed as higher for SLR/Ag-TNP nanocomposites, equated to neat SLR. The nanoindentation investigation shows an excerpt hike in reduced modulus and hardness by the inclusion of Ag-TNP. The resulted thermal analysis discloses that the introduction of Ag-TNP can appreciably augment the glass transition temperature $\left(T_{g}\right)$, and residual char yield of SLR nanocomposites remarkably. Hence, the significant incorporation of as-prepared Ag-TNP can act as effective nanofillers to enhance the thermal and mechanical properties of photo resin.
\end{abstract}

Keywords: nanocomposites; stereolithography 3D printing; semiconducting nanoparticles; mechanical properties; thermal properties; rheological properties

\section{Introduction}

In recent years, Additive or 3D printing technology were noted as remarkable developing democratization of innovation, which guarantees colossal possibilities and has picked up a ton of interests from diverse fields like biomedical science and tissue engineering [1-3], printing electronics [4,5], microfluidics [6], and aerospace composites [7,8], etc. The 3D printing technology lies in the fabrication process, which facilitates the layer by layer structure formation of 3D objects with the assistance of computer-aided design (CAD) data [9]. Rapid prototyping (3D printing), and the complexities facilitated by it, were transfiguring manufacturing, beyond just the geometry of the part, but also the chemistry and microstructure within the part with position-precise properties $[10,11]$. Among all the 3D printing technologies, the stereolithography (SLA) technique was noted as the first patented and most promoted process. The photopolymerization technique acting as a critical 
mechanism of stereolithography 3D printing technology demonstrates superior performance in the manufacturing of 3D constructions with accuracy, rapid curing, and very micro nanoscale resolution with the presence of ultraviolet (UV) light $[12,13]$. In addition, the photopolymerization techniques show excellent striking, as well as modest approaches in the polymer chemistry nowadays [14]. Utilization of solar light as a power source for reactions has made it conceivable to decrease the cost of the manufacturing processes while being eco-friendly [15]. Therefore, the photopolymerization had an exceptional pull around world to the approach of numerous engineering applications such as coatings, printing technologies, dental fillings, and the building 3D structures [16-18]. The SLA technique transforms a multifunctional urethane or acrylic-based monomers and oligomers into an interconnected polymer through propagation reaction, which was initiated by free radicals or cations formed by light illumination [19-21]. Most monomers and oligomers are not able to generate initiating free radicals upon light exposure, and it was crucial to run by with some initiators that will assist in initiate polymerization, through a photochemical reaction [22,23].

Certainly, rapid curing and praiseworthy spatial resolution were observed as most advantageous to this technique, but flimsiness and exceptionally reduced bearing resistance were caused by the serious downsides from non-uniform polymer structural design and bulky cross-linking density, which limit SLA resin applications in many industries [24,25]. However, impressive accomplishments on the arrangement of SLA resins with superior mechanical strength and thermal stability of the 3D printed parts have been acquired by introducing nanofillers like graphene, CNT and nano-sized metal and inorganic particles to the photo resin matrix [26-29], with the effect of loaded nanofillers within the resin matrix being dynamic to make an exceptional interface to enhance interlayer connection, which would prime to higher load allocation to the polymer matrix from the nanofillers, therefore giving an improved reinforcement effect [30-32]. Metal and metal oxide nanoparticles have delighted significant research attention over the recent years [33,34]. Numerous efforts have strived on the preparation of metal-oxide based nanoparticles and their broad applications indecisive from solar cells, electronics, and biosensors to environmental applications such as water refinement and hazardous waste recycling treatments [35-37].

The sustainable, low harmfulness, cheap, high mechanical, and thermal performance of Titanium dioxide nanoparticles (TNP) envisaged as one of the most promising semiconductor photocatalysts for 3D printing applications, wherein it has a lowest electronic bandgap energy of about $3 \sim 3.2 \mathrm{eV}$ that helps to stimulate better photocatalysis reactions under UV light radiation [38,39]. In recent years, various nanostructured $\mathrm{TiO}_{2}$ materials, such as nanoparticles, nanotubes, and nanowires were synthesized via many proposed approaches such as sol-gel, hydrothermal, and anodic oxidation, etc. [40-43]. The photocatalytic process of semiconducting nanoparticles, followed by the formation of active radical species, resulted from the reduction of molecular oxygen $\left(\mathrm{O}_{2}\right)$ by photostimulated electron-hole pairs [44,45]. In addition to TNP, Ag decorated TNP have also been performed as free-radical photoinitiators for curing photo resins, due to their low energy bandgap compared to pristine TNP and proficiency of producing electron-hole pairs which was much needed for the generation of reactive species to improve photopolymerization [46-49]. Many efforts have been made to improve the thermal and mechanical properties of the polymer matrix by the introduction TNP as nanofillers [50,51].

In this work, we emphasize the importance of pioneering coordination of nanotechnology and additive manufacturing technology, which were made a technological revolution in this era to lead immeasurable promises in science and technology. Silver decorated $\mathrm{TiO}_{2}$ (Ag-TNP) is known to be an outstanding photoactive compound that is non-hazardous, cheap, and highly stable [52-54]. Here, we have reported the utilization of Ag decorated semiconducting TNP (Ag-TNP) as an effective initiator for the photopolymerization of acrylic-urethane resin under UV irradiation. Our research outcome was revealing that the Ag-TNP can initiate the photopolymerization of methyl methacrylate (MMA) and polyurethane in organic systems in the presence of UV light irradiation. It further shows that the Ag-TNP can recruit $\mathrm{O}_{2}$ in the polymerization mechanism to avert inhibition of the initiating radicals. 
In addition, this Ag-TNP is able to separate easily from the polymer mixture and reprocessed without any substantial worsening in the photocatalytic activity. This metal-metal oxide semiconducting nanostructured filler helps to attain great dispersion and allow the UV light to penetrate maximum depth within the resin system remarkably. The as-prepared Ag-TNP incorporated SLA 3D printed structure exposes very high mechanical and thermal properties due to the enhanced filler dispersion within the polymer matrix and induced photopolymerization achieved via the lower bandgap energy of the semiconducting metal oxide nanoparticles.

\section{Experimental Procedures}

\subsection{Materials}

Macklin, City, China was supplied with Titanium tetrachloride ( $\mathrm{TiCl}_{4}, \mathrm{GR}, 99.5 \%$ ), the combination of urethane-acrylate based UV curable stereolithography resin which consists of various monomers and oligomers such as CN9010 (Aliphatic urethane acrylate oligomers), (Sartomer America, Exton, PA, USA), CN991 (Aliphatic polyester based urethane diacrylate oligomers), (Sartomer America, USA), SR209 (Tetra ethylene glycol dimethacrylate), (Sartomer America, USA), HEMA (Hydroxy ethyl methacrylate) and HPMA (Hydroxy propyl methacrylate), (Sigma Aldrich, Wuxi, China), TPO (2,4,6-trimethyl benzoyl diphenyl phosphine oxide) (photoinitiator). Silver nitrate $\left(\mathrm{AgNO}_{3}, 99 \%\right.$, ) and Ethanol $\left(\mathrm{C}_{2} \mathrm{H}_{6} \mathrm{O}_{\text {, }}\right.$ AR, Anhydrous, 99.7\%,) were brought from Sigma Aldrich, China. Methyl alcohol $\left(\mathrm{CH}_{4} \mathrm{O}, 99.5 \%\right.$, was purchased from Shanghai Titan Scientific Co. Ltd., Shanghai, China. The coupling agent KH570 (3-Glycidoxypropyl tri-methoxy silane) was procured from Wenhua Chemicals, China. The ultra-pure (DI) water was utilized throughout the research work.

\subsection{Methods}

\subsubsection{Synthesis of Anatase $\mathrm{TiO}_{2} \mathrm{NPs}(\mathrm{TNP})$ and $\mathrm{Ag}-\mathrm{TiO}_{2} \mathrm{NPs}(\mathrm{Ag}-\mathrm{TNP})$}

Anatase $\mathrm{TiO}_{2}$ nanoparticles (TNP) were synthesized via the sol-gel method [55]. In addition, $10 \mathrm{~mL} \mathrm{TiCl}_{4}$ was slowly added dropwise into $100 \mathrm{~mL}$ of absolute ethyl alcohol at room temperature. A significant amount of $\mathrm{HCl}$ gas was exhausted for the period of the mixing process. A light yellow solution was acquired and accumulated for several days (2 to 5 days) to form a sol-gel TNP. Then, this reaction mixture was dehydrated at $70{ }^{\circ} \mathrm{C}$ until a dry powder was achieved. The dry whitish powder was annealed at $400{ }^{\circ} \mathrm{C}$ with a heating rate of $5{ }^{\circ} \mathrm{C} / \mathrm{min}$ for $30 \mathrm{~min}$ to obtain TNP. In order to prepare Ag-TNP, $1 \mathrm{~g}$ of TNP was added to the solution containing $10 \mathrm{~mL}$ of $100 \mathrm{mM} \mathrm{AgNO}$ and $10 \mathrm{~mL}$ of methanol, and the reaction mixture was treated under the irradiation of UV light for $1 \mathrm{~h}$. The solution turns from a milky whitish color to brownish color, which shows the successful decoration of $\mathrm{Ag}$ particles on the surface of $\mathrm{TiO}_{2}$ NPs. Finally, the brownish solution was cleaned by DI water and ethanol followed by dehydration in a hot air over at $80^{\circ} \mathrm{C}$ for $12 \mathrm{~h}$ to achieve Ag-TNP powder [56]. The supplementary Figure S1 represents a detailed schematic illustration of the synthesis process of Ag-TNP.

\subsubsection{Preparation of Nanocomposites for SLA 3D Printing}

To prepare the Ag-TNP incorporated SLA resin nanocomposites, a measured amount of Ag-TNP was treated with coupling agent $\mathrm{KH} 570$ ( $1 \% w / w$ based on filler concentration) in ethanol solution, and dried at $80^{\circ} \mathrm{C}$ in a blast oven for $2 \mathrm{~h}$, prior to the addition with SLA resin to get a better dispersion of Ag-TNP within the photo resin by the assistance of ultrasonication followed by continuous stirring [57]. The loading ratio of Ag-TNP in the following description of this work was expressed as the weight (g) of added Ag-TNP per $100 \mathrm{~g}$ SLR matrix (denoted by $\% w / w$ ). The sample named as SLR for the neat SLA photo resin and the samples, expressed by SLR/Ag-TNP-0.5, represents the loading concentration of $0.5 \mathrm{~g}$ as-synthesized Ag-TNP with the $100 \mathrm{~g}$ of SLA photo resin and the same as for other samples likes SLR/Ag-TNP-0.8, SLR/Ag-TNP-1.0, and SLR/Ag-TNP-1.2. Without specification, 
the incorporation of Ag-TNP in the SLA was stated as the weight percentage (\% $w / w)$, and the as-geared SLR nanocomposites with $k \% w / w$ loading of Ag-TNP were signified by SLR/Ag-TNP-k. The step by step detailed preparation route of SLR/Ag-TNP nanocomposites was demonstrated in the supplementary image Figure S2.

\subsubsection{Fabrication of Three-Dimensional Structures by SLA 3D Printer}

Fabrications of neat SLR and SLR/Ag-TNP composite samples were printed with the aid of a Dream 3D-C200 SLA 3D printer with UV laser irradiation power was about $155 \mathrm{~mW} / \mathrm{cm}^{2}$ and the wavelength of $405 \mathrm{~nm}$ followed (refer to supporting information Figure S3) according to the ASTM standard D638. The laser irradiation was about $155 \mathrm{~mW} / \mathrm{cm}^{2}$ fixed. The scan rate was maintained to $2500 \mathrm{~mm} / \mathrm{s}$. After printing, the samples were sluiced by iso-propanol several times and post-cured for 20 min with the assistance of UV chamber. Figure 1 represents the induced photopolymerization reaction by the incorporation Ag-TNP within SLA 3D printing. The optimized monomers and oligomers compositions of prepared SLA resin were presented with the supplementary Table S1.

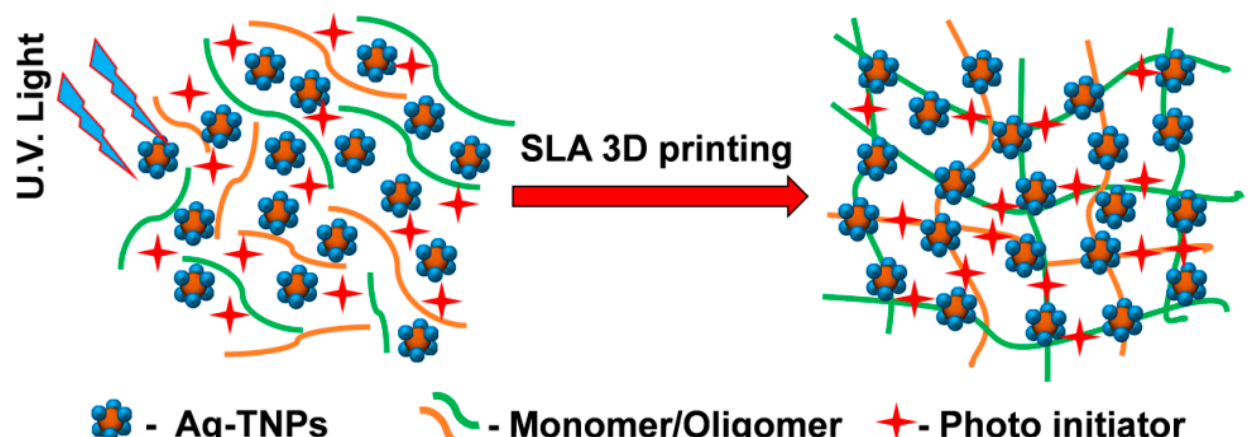

Figure 1. The schematic illustration of the induced photopolymerization of SLR (stereolithography resin) with the incorporated semiconducting $\mathrm{Ag}$ - TNP (Ag decorated $\mathrm{TiO}_{2}$ nanoparticles) hybrids under UV light for SLA (stereolithography) 3D printing.

\subsection{Measurements and Characterization}

The crystalline microstructures phases of as-prepared $\mathrm{TiO}_{2}$ and $\mathrm{Ag}$-TNP were determined by low angle XRD (STOE-STADV diffractometer, STOE Corporation, Chicago, IL, USA) using Cu-K $\alpha$ radiation $(\lambda=1.59041 \AA)$. A Raman spectrum was recorded with the assistance of a Raman Microscope (Renishaw, Invia, New Mills, UK) with a laser excitation wavelength of about $537 \mathrm{~nm}$. The Raman spectra of $\mathrm{TiO}_{2}$ and Ag-TNP powder were observed. The surface composition of elements and electronic states of the Ag-TNP were investigated by using X-ray photon spectroscopy (Thermo Scientific Escalab 250Xi, Waltham, MA, USA). High-resolution transmission electron microscopy (HRTEM) (JEOL JEM-2010, Tokyo, Japan) was engaged to perceive the morphologies of the ultrathin sectioned samples of $\mathrm{Ag}-\mathrm{TiO}_{2} \mathrm{NPs}$ and selected area diffraction patterns (SAED) were determined at an acceleration potential was $200 \mathrm{kV}$. A field emission scanning electron microscope (FESEM) (JSM-7500F, SU8010/EDX, Tokyo, Japan) was intended to observe the morphologies of $\mathrm{Ag}-\mathrm{TiO}_{2} \mathrm{NPs}$, and the fractured surfaces of 3D printed samples after performing the tensile strength analysis. A UV light auxiliary of DHR-2 (Discovery Hybrid Rheometer-2, TA instrument, New Castle, DE, USA) was employed to examine the Rheological study of neat SLR and SLR/Ag-TNP samples. A UV light appurtenant was expended for the dynamics examines of the curing procedure. The series of steady-state shear speed was followed from the range about 0.1 to 100 per seconds, and the temperature was maintained at $25^{\circ} \mathrm{C}$. The upper and lower geometry was prepared by aluminum and a transparent PMMA (Poly methyl methacrylate), respectively, with a diameter about $20 \mathrm{~mm}$ for each. The investigation was performed for $80 \mathrm{~s}$ in total, and the light source was switched $\mathrm{ON}$ at the 30 th second with $155 \mathrm{~mW} / \mathrm{cm}^{2}$ irradiation power being maintained. Thermogravimetric analysis (TGA) was performed by the assistance of TA Instruments 
STA449C (New Castle, DE, USA) to examine the thermal stability of the 3D printed samples of neat SLR and SLR/Ag-TNP with different concentrations. Each testing was performed about 5-10 $\mathrm{mg}$, and the analyzing temperatures were maintained at starting from $25^{\circ} \mathrm{C}$ to $800^{\circ} \mathrm{C}$ with an increasing heat rate of $10^{\circ} \mathrm{C} / \mathrm{min}$ under a nitrogen atmosphere.

Thermo-mechanical analysis or dynamic mechanical analysis (DMA) of neat SLR and SLR/Ag-TNP 3D printed specimens were investigated by the aid of DMA Q800 System (TA Instruments, New Castle, $\mathrm{DE}, \mathrm{USA}$ ) using double cantilever mode. The testing temperature was performed from $25^{\circ} \mathrm{C}$ to $180{ }^{\circ} \mathrm{C}$ at a heating rate of $5{ }^{\circ} \mathrm{C} / \mathrm{min}$ at a frequency about $1 \mathrm{~Hz}$. The wavelength of the light absorbance by the materials and its bandgap energy was investigated via the Diffusive Reflectance Spectroscopy (DRS) (PerkinElmer Lambda 950 UV/VIS/NIR spectroscopy, Borken, Germany) instrument. The bandgap energy of as-prepared $\mathrm{TiO}_{2}$ and $\mathrm{Ag}-\mathrm{TiO}_{2}$ was determined by using a mathematical approach of the Kubelka-Munk function. The mechanical properties of neat SLR and SLR/nanofillers 3D printed specimens were analyzed with the help of a universal testing machine, made by AGX-100 plus, Shimadzu, City, Japan. The samples (length $60 \mathrm{~mm} \times$ thickness $2 \mathrm{~mm} \times$ gauge distance $45 \mathrm{~mm}$ ) were tested at a strain rate of $5 \mathrm{~mm} / \mathrm{min}$. To a better understanding, the five sets of samples were analyzed for each group of different concentrations. The nanoindentation study was carried out by a nanoindenter apparatus (Hysitron Inc., Tribo Indenter 750, Minneapolis, MN, USA) with an assistance of 3-regions Berkovich diamond indenter and the radius of the indenter probe was fixed at $50 \mathrm{~nm}$. A sample size with $8 \times 8$ indentations were performed for each sample and the space between two corresponding indentations was set as $10 \mu \mathrm{m}$. Thermal conductivity of the as-prepared neat SLR and SLR/nanofillers 3D printed samples were calculated by TC 3000 thermal conductivity tester (XiatechInstrument Factory, Beijing, China) with the aid of a transient hot-wire method at room temperature. The dimensions of each sample length $30 \mathrm{~mm} \times$ width $10.00 \mathrm{~mm}$ were maintained. The photo kinetic study was investigated with the assistance of a real-time FTIR instrument for the neat SLR and SLR/nanofillers, in order to determine the photopolymerization process enhancement by the incorporation of $\mathrm{Ag}-\mathrm{TiO}_{2}$ nanoparticles. The real-time curing process was carried out for different time interval about $10 \mathrm{~s}, 30 \mathrm{~s}$, $60 \mathrm{~s}, 120 \mathrm{~s}, 240 \mathrm{~s}, 400 \mathrm{~s}$, and $600 \mathrm{~s}$, respectively. Different power energy was also utilized to analyze the kinetic study of the SLR/nanofillers blends.

\section{Results and Discussion}

\subsection{Characterization of $\mathrm{Ag}-\mathrm{TiO}_{2}$ Nanoparticles (Ag-TNP)}

XRD investigated the crystalline structure and phase of the as-prepared $\mathrm{TiO}_{2}$ and $\mathrm{Ag}-\mathrm{TNP}$, and the testing was carried out with the range of $2 \theta$ lies between $10^{\circ}-70^{\circ}$. Figure $2 \mathrm{a}$ depicts the XRD patterns of $\mathrm{TiO}_{2}$ (refer black patterns in Figure 2a) and Ag-TNP (refer red patterns in the Figure 2a), the pristine $\mathrm{TiO}_{2}$ exhibited firm diffraction peaks at $25.4^{\circ}, 37.2^{\circ}, 37.86^{\circ}, 38.58^{\circ}, 48.18^{\circ}, 53.95^{\circ}, 55.22^{\circ}, 62.83^{\circ}$, and $68.91^{\circ}$ corresponding to the planar structures of (101), (103), (004), (112), (200), (105), (211), (204), and (116), respectively, and the observed planar was perfectly matched and confirmed with phases of tetragonal anatase $\mathrm{TiO}_{2}$ (JCPDS card no: 21-1272). In the case of Ag-TNP, XRD patterns exhibited additional reflections at $2 \theta$ values about $38.03^{\circ}, 44.33^{\circ}$, and $64.48^{\circ}$, which can be attributed to the crystal planes of metallic silver (111), (200), and (200), respectively, and the noted crystalline planar was matched and confirmed with the characteristics of fcc (face-centred cubic) metal (JCPDS card no: 89-3722) nanoparticles about 5 to $10 \mathrm{~nm}$ in diameter [58]. The above results were confirming that the Ag particles were successfully decorated on the surfaces of the $\mathrm{TiO}_{2} \mathrm{NPs}$. 

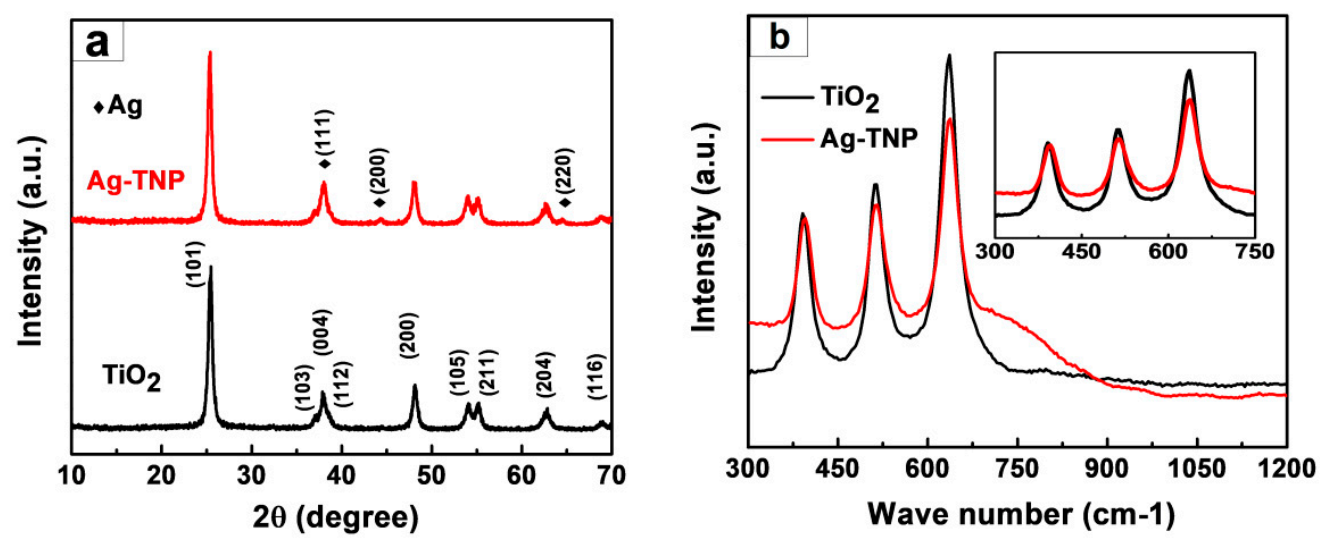

Figure 2. The crystalline structure analysis of as-prepared $\mathrm{TiO}_{2}$ and $\mathrm{Ag}$-TNP hybrids (a) $\mathrm{X}$-ray diffraction peaks of unmodified $\mathrm{TiO}_{2}$ (black pattern), Ag-TNP (red pattern), and (b) Raman spectrum of $\mathrm{TiO}_{2}$ (black spectrum) and Ag-TNP (red spectrum), inset in (b) shows the enlarged view of the Raman spectrum at the wavelength range of 300 to 750 .

Raman spectroscopy analysis was performed to investigate the successful ornamentation of $\mathrm{Ag}$ $\mathrm{NPs}$ on the surfaces of $\mathrm{TiO}_{2} \mathrm{NPs}$. Figure $2 \mathrm{~b}$ demonstrates the Raman spectrum of the $\mathrm{TiO}_{2}$ (refer to the black spectrum in Figure 2b) and Ag-TNP (refer to the red spectrum in Figure 2b). The Raman spectrum of $\mathrm{TiO}_{2}$ polymorphs was unique enough, and they were beneficial for distinguishing various $\mathrm{TiO}_{2}$ phases. The $\mathrm{TiO}_{2} \mathrm{NPs}$ demonstrated Raman bands observed at $391.2 \mathrm{~cm}^{-1}, 514.6 \mathrm{~cm}^{-1}$, and $636.4 \mathrm{~cm}^{-1}$ were associated with the $\mathrm{B} 1 \mathrm{~g}$, $\mathrm{A} 1 \mathrm{~g}$, and Eg Raman modes of anatase $\mathrm{TiO}_{2}$, respectively. Conversely, the Ag-TNP Raman spectrum also expresses the Raman bands the same as $\mathrm{TiO}_{2}$, but, with the slight deviation, was observed in Eg Raman mode, which was shifted from $636.4 \mathrm{~cm}^{-1}$ to $637.5 \mathrm{~cm}^{-1}$ (refer to the inset graph in Figure $2 b$ ). The observed red-shifting of Eg Raman mode on the Ag-TNP spectrum confirmed that $\mathrm{Ag}$ nanoparticles successfully decorated the $\mathrm{TiO}_{2}$ surfaces [59].

The X-ray photoelectron spectroscopy (XPS) was a great tool to investigate the composition of elements and electronic states of the samples. The performed XPS analysis graphs were depicted with the supplementary Figure S4. The resulted XPS survey spectrum of pristine $\mathrm{TiO}_{2}$ (refer to the black line in Figure S4a) and Ag-TNP (refer to the red line in Figure S4a) were displayed in Figure S4a. In the case of the $\mathrm{TiO}_{2}$ survey spectrum, there was no observation of the $\mathrm{Ag}$ absolute peak, but the $\mathrm{Ti}($ at $460 \mathrm{eV})$ and $\mathrm{O}($ at $531 \mathrm{eV})$ peaks were noted. However, the Ag-TNP survey spectrum exposing the presence of $\mathrm{Ti}, \mathrm{Ag}$ and $\mathrm{O}$ elements was ensured by the intensive peaks around $460 \mathrm{eV}\left(\mathrm{Ti} 2 \mathrm{P}_{3 / 2}\right.$ at $459.37 \mathrm{eV}$ and Ti $2 \mathrm{P}_{1 / 2}$ at $\left.465.13 \mathrm{eV}\right), 370 \mathrm{eV}(368.1,374.1)$, and $531 \mathrm{eV}(\mathrm{O}-\mathrm{Ti}$ at530.60 eV and O-H at $531.98 \mathrm{eV}$ ) binding energy, respectively, in the $\mathrm{TiO}_{2}$ samples with its significant contribution. The experiential results of the XPS survey spectrum confirming that the successful adornment of Ag nanoparticles on the surfaces of $\mathrm{TiO}_{2}$ NPs. Moreover, the deconvoluted XPS spectra of $\mathrm{Ti}, \mathrm{Ag}$, and $\mathrm{O}$ were displayed in Figure $\mathrm{S} 4 \mathrm{~b}, \mathrm{c}, \mathrm{d}$, respectively. The $\mathrm{Ag} 3 \mathrm{~d}_{3 / 2}$ and $\mathrm{Ag} 3 \mathrm{~d}_{5 / 2}$ peaks were fruitfully indicated in the presence of Ag in Ag-TNP.

HRTEM and FESEM images investigated surface morphology and particle size distributions of as-prepared pristine $\mathrm{TiO}_{2}$ and $\mathrm{Ag}$-TNP. The samples were dispersed with pure ethanol and drop-casting on a copper grid before analysis. The pristine tetrahedral $\mathrm{TiO}_{2} \mathrm{NPs}$ were clearly observed with the HRTEM image of Figure 3a,b, with slight agglomeration. However, Figure $3 \mathrm{~d}-\mathrm{f}$ express an experiential HRTEM image of the Ag-TNP with different magnification, which embraced the great agglomeration of approximately tetragonal $\mathrm{TiO}_{2}$ and spherical Ag NPs having mean diameters about $30-40$ and 5-10 nm, respectively (refer to Figure 3f). For a better understanding, the as-prepared Ag-TNPs were investigated through higher magnification about $5 \mathrm{~nm}$ to analyze the single $\mathrm{Ag}$ modified $\mathrm{TiO}_{2}$ hybrids, and the resulting image was displayed in Figure 3g. Lattice fringes and associated d-spacing (refer to Figure 3c) were consistent with different planes of tetragonal anatase, with the help of the SEM-EDS report confirming that the Ag-TNP were possessed exclusively of $\mathrm{Ti}, \mathrm{Ag}$, and $\mathrm{O}$ (refer 
to Figure 3i). The Ag-TNP sample had higher contrast and spherical Ag nanoparticles of 5-10 nm diameters, which appear to embellish on the larger surface of $\mathrm{TiO}_{2}$ crystallites uniformly. The analysis of lattice fringes reveals that d-spacing consistent with the planes of the tetragonal structure of anatase $\mathrm{TiO}_{2}$ and the planes of spherical Ag NPs, and hence these smaller particles were attributed to metallic Ag nanoparticles. Figure $3 \mathrm{c}$ is the SAED pattern of the Ag-TNP generated in HRTEM, which exhibits high crystalline structure and planes. Moreover, the surface morphology study of Ag-TNP was proved that the Ag nanoparticles were successfully accumulated on the $\mathrm{TiO}_{2}$ surfaces. In addition to that, Figure $3 i$ expresses the SEM-EDS results of as-prepared Ag-TNP hybrids, and the results revealed that the elemental composition present in the Ag-TNP, while screening that the Ti, $\mathrm{O}$, and Ag elements were only present within the Ag-TNP hybrids, confirmed that the Ag nanoparticles were successfully festooned on the $\mathrm{TiO}_{2}$ surfaces.

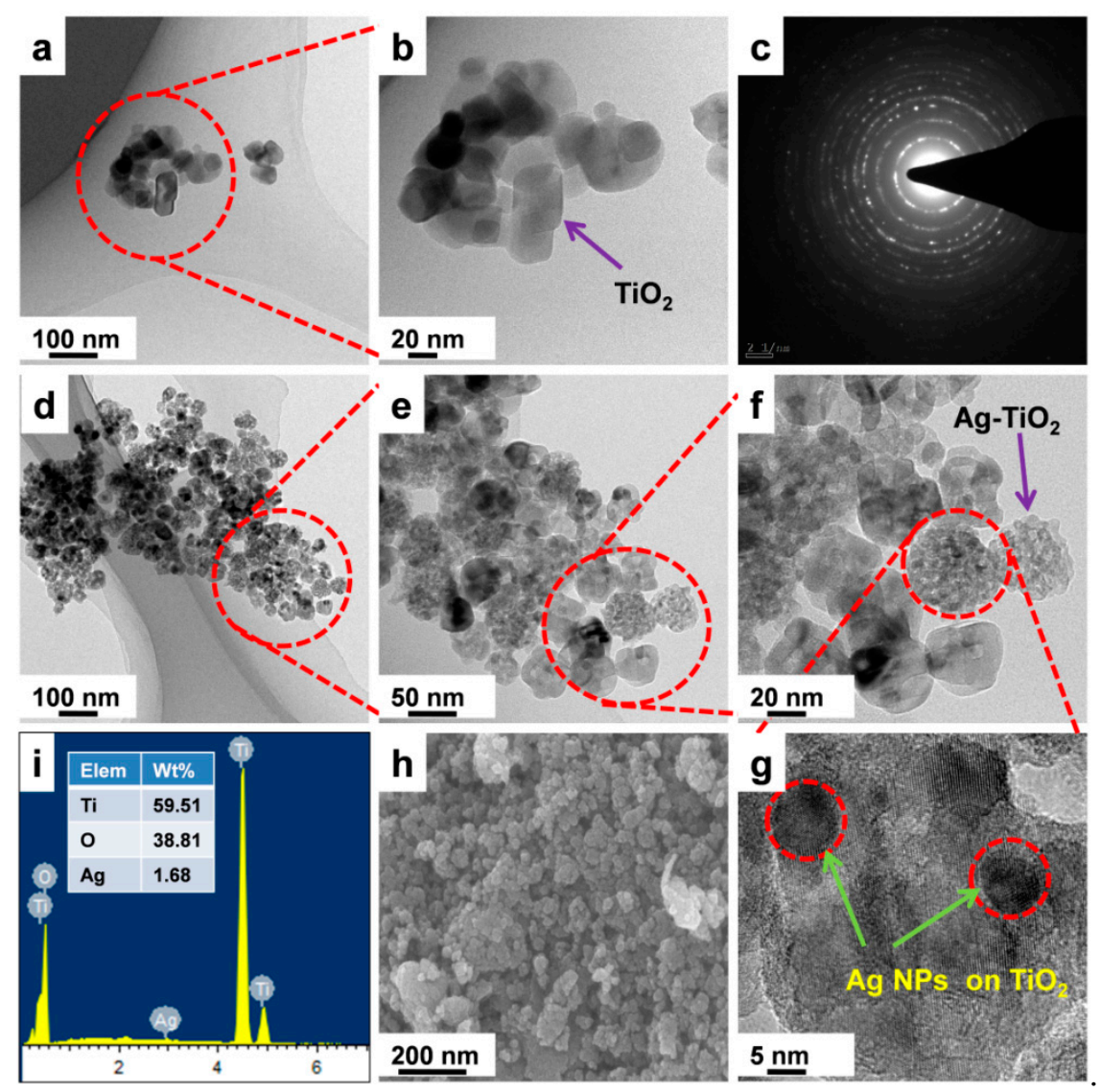

Figure 3. Structural Morphology study analysis of as-prepared $\mathrm{TiO}_{2} \mathrm{NPs}$ and Ag-TNPs hybrids. (a) unmodified $\mathrm{TiO}_{2}$, (b) neat $\mathrm{TiO}_{2}$ at higher magnification about $20 \mathrm{~nm}$, (c) the SAED pattern of Ag-TNPs, (d) Ag nanoparticles modified $\mathrm{TiO}_{2}$, (e) and (f) higher magnification of Ag-TNPs hybrid, (g) a single particle magnification of Ag-TNPs, (h) FESEM image of Ag-TNP, (i) SEM-EDS report of Ag-TNP.

The diffusive reflectance spectroscopy (DRS) was an effective analysis to determine the energy bandgap of semiconducting $\mathrm{TiO}_{2}$, and Ag-TNP using the Kubelka-Munk equation, and the calculated results were presented in Figure 4. According to the analysis, the Kubelka-Munk function F(R) allowed the UV absorbance of the semiconducting metal-metal oxide NPs to be estimated from its reflectance (R) according to the following equation:

$$
F(R)=(1-R)^{2} / 2 R
$$


The bandgap measurement was done by the slope of the Tauc's curve linearly extended towards the point, where the line intersects the horizontal energy axis employing the subsequent Tauc's plot appearance when supposing that $\mathrm{TiO}_{2}$ was an indirect bandgap semiconductor:

$$
(\mathrm{F}(\mathrm{R}) \cdot h v)^{1 / 2}=\mathrm{A}(h v-\mathrm{Eg})
$$

where $\mathrm{A}, h$, and $v$ were a constant, the Planck constant, and the frequency, respectively $[60,61]$.

From the graph (refer to Figure 4), it was precisely measured that the bandgaps of $\mathrm{TiO}_{2}$ and Ag-TNP were $3.1 \mathrm{eV}$ and $2.9 \mathrm{eV}$, respectively, and also the inset of Figure 4 expressed that the Ag-TNP exhibited a stronger, red-shifted absorbance than $\mathrm{TiO}_{2}$ NPs. The lowest energy bandgap would help the semiconducting Ag-TNP undergo rapid and enormous generation of hole-electron pairs under the UV light, which triggers the vast and robust polymerization throughout the photo resin [62].

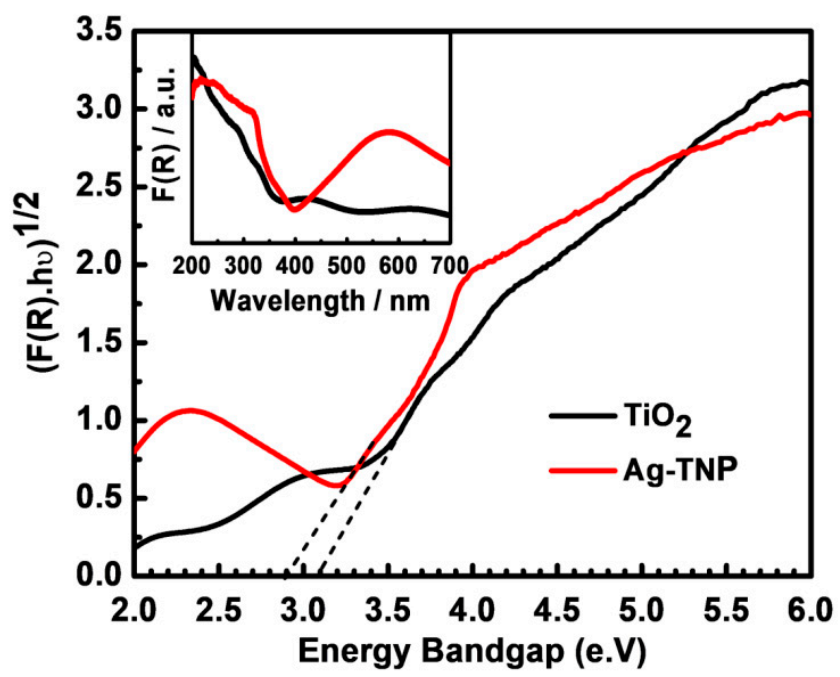

Figure 4. The diffusive reflectance analysis of as-prepared $\mathrm{TiO}_{2}$ and $\mathrm{Ag}$ modified $\mathrm{TiO}_{2}$ hybrids to obtained Tauc's plot for an indirect bandgap model (Kubelka-Munk function). The red line belongs to Ag-TNP hybrids, and the black line belongs to unmodified $\mathrm{TiO}_{2}$ nanoparticles. The dash-dot lines represent the tangent line towards the point, where the line intersects the horizontal energy axis (bandgap). The inset graph shows the enlarged version of the bandgap model study.

\subsection{Characterization of SLR/Ag-TNP Nanocomposites}

The UV LED assisting DHR-2 investigation was carried out before the mechanical property analysis of the neat SLR and SLR/Ag-TNP nanocomposites, in order to examine the effects of incorporated Ag-TNP curing behaviors with the SLA resin matrix. The DHR-2 analysis outcome reveals that the SLR/Ag-TNP nanocomposites own an elevated viscosity compared to neat SLR, and the viscosity shows an increase as the loading percentage of Ag-TNP increases from $0.5 \%$ to $1.2 \% w / w$ (refer to Figure 5a). Moreover, the DHR-2 operational with a UV LED co-conspirator instrument can be traced as the variations in storage modulus of the nanocomposite resin in the course of the curing route by a fast sampling process. Figure $5 \mathrm{~b}$ demonstrates the curing behaviors of neat SLR and SLR contains with different loading \% w/w of Ag-TNP. The following protocol was strictly maintained for DHR-2 analysis of tested samples, and the resulting outcomes were experiential in the following trend, which means that, prior to the UV light being switched ON (at time $<30 \mathrm{~s}$ ), the storage modulus of all samples stands for the homogeneous storage modulus, meaning that there were no notable storage modulus changes in the uncured resin. However, once the UV light was switched ON (at time $=30 \mathrm{~s}$ ), the outstanding increasing trend of storage modulus was renowned, signifying that the cross-linking reaction has proceeded remarkably. After UV curing (at time $\approx 50 \mathrm{~s}$ ), the cross-linking and curing responses were observed as a saturation level, and the storage modulus was kept in a 
maximum state and remained steady. The excellent storage modulus was achieved at the loading concentration of $1.0 \% \mathrm{w} / \mathrm{w}$ Ag-TNP (refer to the violet line in insert Figure $5 \mathrm{~b}$ ). The resulting graph (refer to Figure $7 b$ ) revealed that the UV light may evade the well-dispersed minuscule Ag-TNP very quickly, especially at $1.0 \% w / w$ of loading concentration with an SLR matrix. Nevertheless, the accumulation of Ag-TNP would obstruct the light and inhibit the photopolymerization in the SLR system $[63,64]$. Consequently, as the incorporation of Ag-TNP hybrids reaches 1.2\% w/w, significant protracted escalation of polymerization and an apparent decline of curing rate was distinguished. For the UV-instigated photopolymerization and interconnection, the nanoparticles fillers affect the gel time in two contradictory features: (a) the reinforcing effect of nanoparticles may endorse the interconnection between the monomers and oligomers to enhance the modulus of resin matrix, hence reducing the gel period; (b) the nanofillers may obstruct the light, hindering the photopolymerization, and thus extend the gel period [65]. Figure 5b depicts that the accumulation of Ag-TNP lengthens the gel time a little bit, though the highest storage modulus was observed since it was subjected to the strengthening effect (refer to the purple line in Figure 5b).
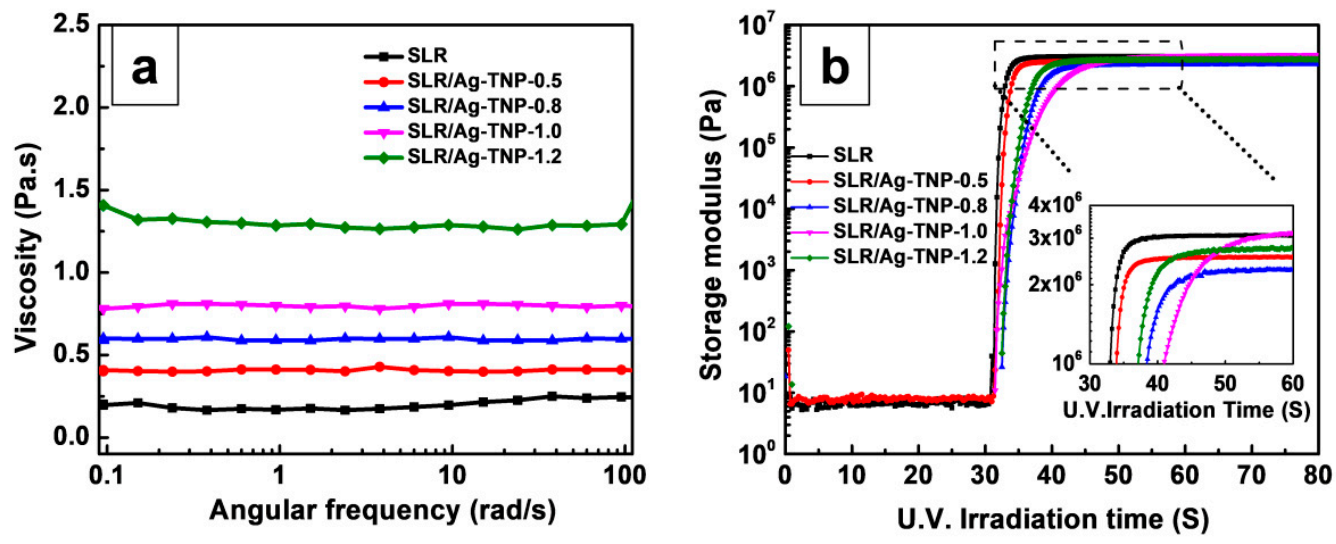

Figure 5. The DHR-2 UV LED analyses of neat SLR and SLR/Ag-TNP nanocomposites (a) viscosity variations of SLR/Ag-TNP and neat SLR nanocomposites as a role of shear speed at different concentrations of Ag-TNP loading, (b) the consequence of Ag-TNP on the dynamics of the UV light curing response. The mini insert graph in the (b) was an engorged sight of the curves among time $=30$ to $60 \mathrm{~s}$ (a black dotted rectangular line marked the exact focused area).

\subsubsection{Mechanical Properties}

The mechanical behaviors of the SLR/Ag-TNP and neat SLR, performed with the assistance of the universal testing machine and the observed results, were discussed in this subsection. The tensile and flexural stress-strain curves of the stated dog-bone shaped 3D printed samples of neat SLR, and SLR/Ag-TNP nanocomposites were displayed with Figure $6 \mathrm{a}, \mathrm{b}$. For a better understanding of the effects of incorporated Ag-TNP with an SLR matrix, mechanical properties enhanced the complete data set of tensile strength and a tensile modulus graph as depicted in Figure $6 \mathrm{c}, \mathrm{d}$. The tensile strength of the SLR/Ag-TNP nanocomposites revealed an increasing trend, with increasing loading concentration of Ag-TNP. Especially at the loading content of 1.0\% w/w, Ag-TNP shows remarkable tensile strength enhancement compared with neat SLR. The enhanced tensile strength of SLR/Ag-TNP was noted as 44.7 $\mathrm{MPa}$ at the $1.0 \% \mathrm{w} / \mathrm{w}$ incorporation of as-prepared Ag-TNP, which shows a $60.8 \%$ enhancement compared with neat SLR (27.8 MPa) (refer to the red line in Figure 6c). In addition, the increased tensile modulus was also being observed with the increasing Ag-TNP loading with the SLR matrix (refer to the blue line in Figure 6c). In addition, Figure 6e demonstrates the elongation at break analysis of the neat SLR and SLR/nanofillers nanocomposite, which illustrates that the elongation at break reduces with escalating of the nanofillers (Ag-TNPs) content. The integrated nanofillers may confine the SLR chain segmental mobility to improve the inflexibility of the polymer matrix and make the SLR system more brittle, and then lastly directs to the destitute elongation at break [66]. 
Concurrently, the ductility of the SLR nanocomposites was abridged while inserting the reinforcing nanofillers into the SLR system, which would appreciably diminish the stress transfer $[25,61]$ and make the SLR system more fragile with inferior ductility caused by the more complicated chain mobility by the rigidity nature of the incorporated nanofillers [62,67]. However, the incorporated nanofillers (Ag-TNPs) render striking enrichment in mechanical properties, owing to their incredible mechanical properties [68,69]. The ductility of 3D printed SLR/Ag-TNP-1.2 (2.9) was reduced 40.8\% less than the $3 \mathrm{D}$ printed neat SLR (4.9). The increasing mechanical properties were observed with the incorporation of increasing Ag-TNP, but the unexpected decrement was noted when the loading concentration goes beyond $1.0 \% w / w$ of Ag-TNP. This crucial phenomenon was maybe the possible agglomeration of Ag-TNP within the SLR matrix when the incorporation goes to a higher level. However, the better mechanical enhancement was achieved at lower content assimilation of Ag-TNP $(1.0 \% w / w)$, due to the homogenous dispersion of incorporated Ag-TNP. Moreover, the low energy bandgap, high crystalline structure, and elevated dispersion of Ag-TNP within the SLR matrix, which helps with the rapid generation of electron-hole pairs and could enhance photopolymerization by a strong bonding with the monomers and oligomers present in the urethane-acrylate photo resin. Hence, the as-prepared Ag-TNP being able to induce the catalytic activity of photopolymerization along with the nanoscale-sized Ag-TNP that can achieve excellent dispersion within the SLR matrix were the key reasons for the mechanical properties enhancement.
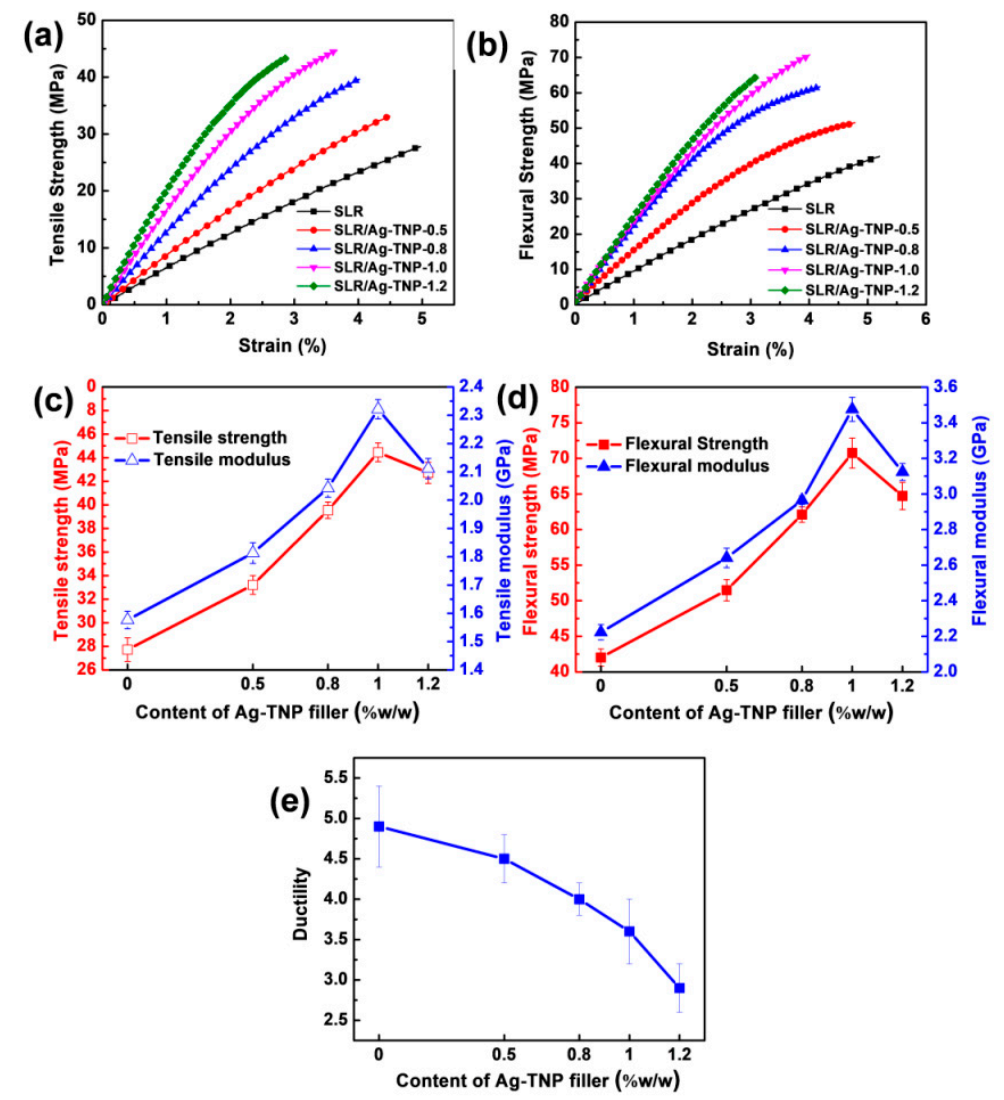

Figure 6. The mechanical properties analysis of neat SLR and SLR/nanofillers. (a) the comparative tensile strength analysis of SLR/Ag-TNP at different concentrations, (b) the comparative flexural strength analysis of SLR/Ag-TNP at different concentrations, (c) the complete data set of tensile study analysis of neat SLR and SLR/Ag-TNP nanocomposites, (d) flexural strength and flexural modulus, with SLA 3D printed samples prepared with various concentration SLR/Ag-TNP, and (e) the ductility study analysis of SLR/Ag-TNP at different concentrations. 
The flexural strength and flexural modulus correlation graph of neat SLR and SLR/Ag-TNP were displayed in Figure 6d. The resulting graph showed that, as the loading \% $w / w$ of Ag-TNP increases, the flexural strength and flexural modulus increase progressively until $1.0 \% w / w$, although the sudden decrement was noted when the loading content increased beyond the $1.0 \% \mathrm{w} / \mathrm{w}$ concentration of Ag-TNP (refer to redline in Figure 6d). The flexural strength and flexural modulus of the 3D printed samples of neat SLR were observed as the lowest compared to all the SLR/Ag-TNP nanocomposites. Overall, the sample SLR/Ag-TNP-1.0 shows the adequate flexural strength and flexural modulus among all the other samples with an increment of $71.8 \%$ and $59 \%$, respectively, compared to that of neat 3D printed SLR. The elevated loading of Ag-TNP (higher than $1.0 \% w / w$ ) would pile into the SLR system, which caused the lower cross-linking density existing in SLA nanocomposites, directing to a weakening of mechanical behaviors of SLR/Ag-TNP nanocomposites, which results in the diminution of flexural and tensile properties [70]. In order to understand the mechanical properties enhancement in a better way, the flexural strength, tensile strength, \% elongation at break, and Young's modulus of the neat SLR and SLR/Ag-TNP nanocomposites were endowed with Tables 1 and 2, subsequent to the effects with Figure $6 c, d$, respectively.

Table 1. The tensile strength and tensile modulus of SLR/Ag-TNP and neat SLR nanocomposites.

\begin{tabular}{cccc}
\hline \multirow{2}{*}{ Sample } & \multicolumn{2}{c}{ Tensile Properties } & \multirow{2}{*}{ Strain (\%) } \\
& Strength $\mathbf{( M P a )}$ & Modulus (GPa) & \\
\hline Neat SLR & $27.8 \pm 1.3$ & $1.5 \pm 0.2$ & $4.9 \pm 0.5$ \\
SLR/Ag-TNP-0.5 & $33.2 \pm 0.8$ & $1.8 \pm 0.1$ & $4.5 \pm 0.3$ \\
SLR/Ag-TNP-0.8 & $39.7 \pm 1.1$ & $2.0 \pm 0.1$ & $4.0 \pm 0.2$ \\
SLR/Ag-TNP-1.0 & $44.7 \pm 0.9$ & $2.3 \pm 0.1$ & $3.6 \pm 0.4$ \\
SLR/Ag-TNP-1.2 & $43.5 \pm 0.8$ & $2.1 \pm 0.1$ & $2.9 \pm 0.3$ \\
\hline
\end{tabular}

SLR: Stereolithography resin; Ag-TNP: Ag decorated $\mathrm{TiO}_{2}$ nanoparticles

Table 2. Results of flexural strength and flexural modulus of SLR/Ag-TNP and neat SLR nanocomposites.

\begin{tabular}{cccc}
\hline \multirow{2}{*}{ Sample } & \multicolumn{2}{c}{ Flexural Properties } & \multirow{2}{*}{ Strain (\%) } \\
& Strength $(\mathbf{M P a})$ & Modulus (GPa) & \\
\hline Neat SLR & $42.0 \pm 1.2$ & $2.2 \pm 0.10$ & $5.2 \pm 0.3$ \\
SLR/Ag-TNP-0.5 & $51.5 \pm 1.5$ & $2.6 \pm 0.05$ & $4.8 \pm 0.2$ \\
SLR/Ag-TNP-0.8 & $62.1 \pm 1.1$ & $2.9 \pm 0.10$ & $4.3 \pm 0.4$ \\
SLR/Ag-TNP-1.0 & $70.7 \pm 2.1$ & $3.5 \pm 0.10$ & $4.0 \pm 0.4$ \\
SLR/Ag-TNP-1.2 & $64.7 \pm 1.9$ & $3.1 \pm 0.05$ & $3.1 \pm 0.5$ \\
\hline
\end{tabular}

For the better perception of the mechanical improvement over the effect of Ag-TNP on the SLR/Ag-TNP nanocomposites, the crack surfaces of the tested tensile trials of neat SLR and SLR/Ag-TNP were investigated by the assistance of FESEM analysis, and the observed morphology images were presented with the Figure 7. The fracture surfaces of neat SLR (refer to Figure 7a) were noted as moderately even and very smooth surfaces had few linear fissures, whereas the fractured surfaces of the SLR/Ag-TNP nanocomposites (refer to Figure $7 \mathrm{~b}-\mathrm{e}$ ) were observed with uneven and rough surfaces having some tears without linear cracks. Performing as stress concentrators, the incorporated subsistence of Ag-TNP may power the tear to proliferate along a convoluted path and promote the configuration of numerous micro-fissures. However, when the loading of Ag-TNP increases to 1.2\% $w / w$, the agglomeration of Ag-TNP was noticed remarkably, which may affect the curing followed by a cross-linking process of the SLR and persuade the development of micro-breakdowns, ensuing with a worsening of mechanical behaviors, together with a considerable lessening in tensile properties (refer to Figure $6 \mathrm{c}$ and Table 1) and flexural properties (refer to Figure $6 \mathrm{~d}$ and Table 2). 

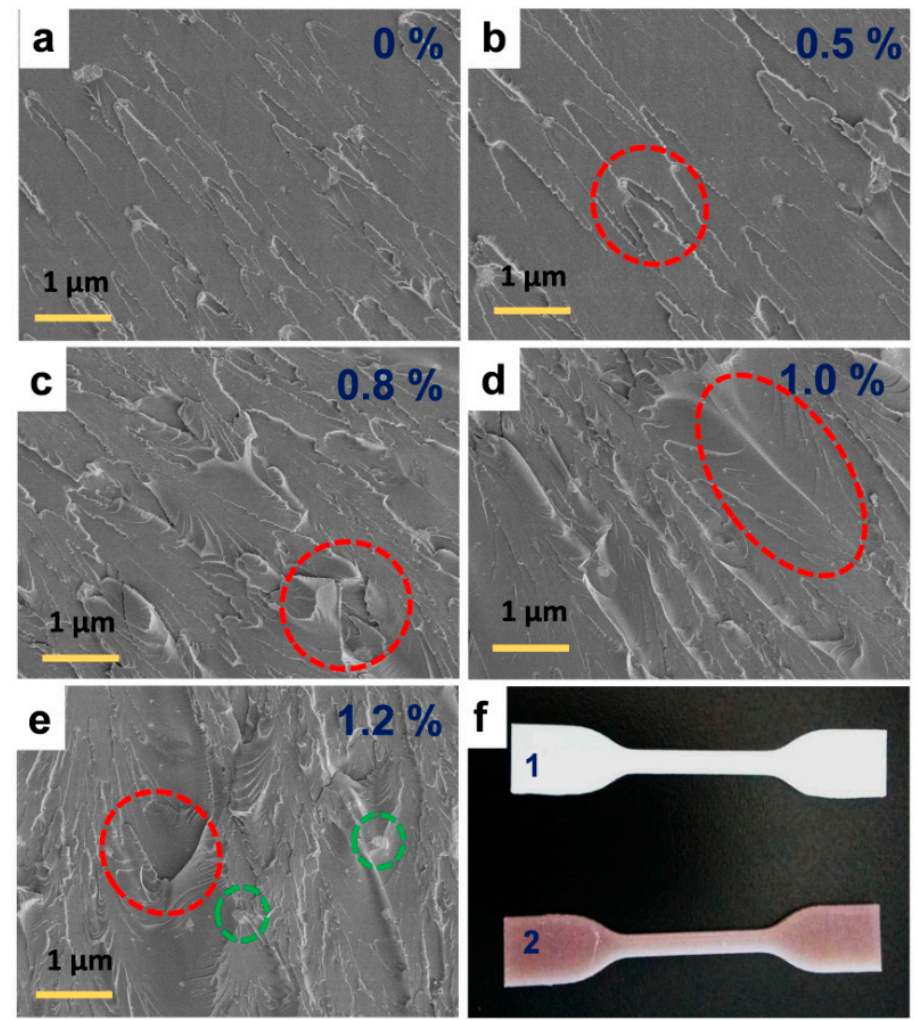

Figure 7. FESEM fracture surface analysis of tensile tested dog-bone specimens of SLA 3D printed samples: (a) neat SLR (smooth and less fissure surface), (b) SLR/Ag-TNP-0.5, (c) SLR/Ag-TNP-0.8 (the marked redline circles represents the uneven cracks), (d) SLR/Ag-TNP-1.0 (the highlighted redline demonstrates the uniform dispersion and high rough surface), (e) SLR/Ag-TNP-1.2 (the highlighted redline circles shows high roughness and the marked green area representing the possible agglomeration of incorporated Ag-TNP nanoparticles), (f) the digital photography of 3D printed dog-bone shaped SLA model samples for tensile strength before analysis (1) neat SLR and (2) SLR/Ag-TNP-1.0 sample.

The nanoindentation analysis was demonstrated to examine the micro-mechanical behaviors of the 3D printed samples of neat SLR and SLR/Ag-TNP nanocomposites on a small scale, for instance, hardness and reduced modulus. Figure 8a represents a plot of the applied load adjacent to the indentation intensity for the SLR/Ag-TNP and neat SLR nanocomposites. In conformity with Figure 8a, expressing that all the SLR/Ag-TNP nanocomposites' indentation depths were recorded as reduced spectacularly compared to the neat SLR nanocomposites. The indentation depths for the SLR/Ag-TNP nanocomposites declined as the addition of Ag-TNP increased with the loading of Ag-TNP up to $1.0 \% \mathrm{w} / \mathrm{w}$; later, the privileged indentation depth was observed when the loading goes beyond $1.0 \% w / w$ of Ag-TNP, which determines that the enhancement of micro-mechanical behavior for the Ag-TNP incorporated SLR nanocomposites was active at the lowest loading content of Ag-TNP. The privileged indentation depth of beyond $1.0 \%$ w/w loaded Ag-TNP may be the inhibition of the plastic deformation rising because of the agglomeration of nanofillers within the SLR nanocomposites. Figure $8 \mathbf{b}$ demonstrates the reduced modulus, and hardness of the 3D printed samples of SLR/Ag-TNP and pure SLR nanocomposites concerning the different loading percentages of Ag-TNP to the SLR nanocomposites. As the increasing incorporation of Ag-TNP varies from 0.5 to $1.0 \% w / w$, the hardness and the reduced modulus were monitored as remarkable increases. By the addition of $1.0 \% w / w$ of Ag-TNP into the SLR matrix, the hardness $(0.225 \mathrm{GPa})$ and reduced modulus ( $3.86 \mathrm{GPa})$ attained the optimized standards and increased by $40.6 \%$ and $34.9 \%$, equating to the neat SLR $(0.16 \mathrm{GPa}$ for hardness and $2.86 \mathrm{GPa}$ for reduced modulus), respectively. However, through promoting the increasing of Ag-TNP afar 1.0\% $w / w$, the hardness and reduced modulus values decrease due to the agglomeration of elevated content of Ag-TNP, which leads to the weak interaction between the SLR matrix and Ag-TNP. 
The experimental results of indentation depth, hardness, and reduced modulus of the SLR/Ag-TNP and pure SLR nanocomposites were supplied with Table 3.
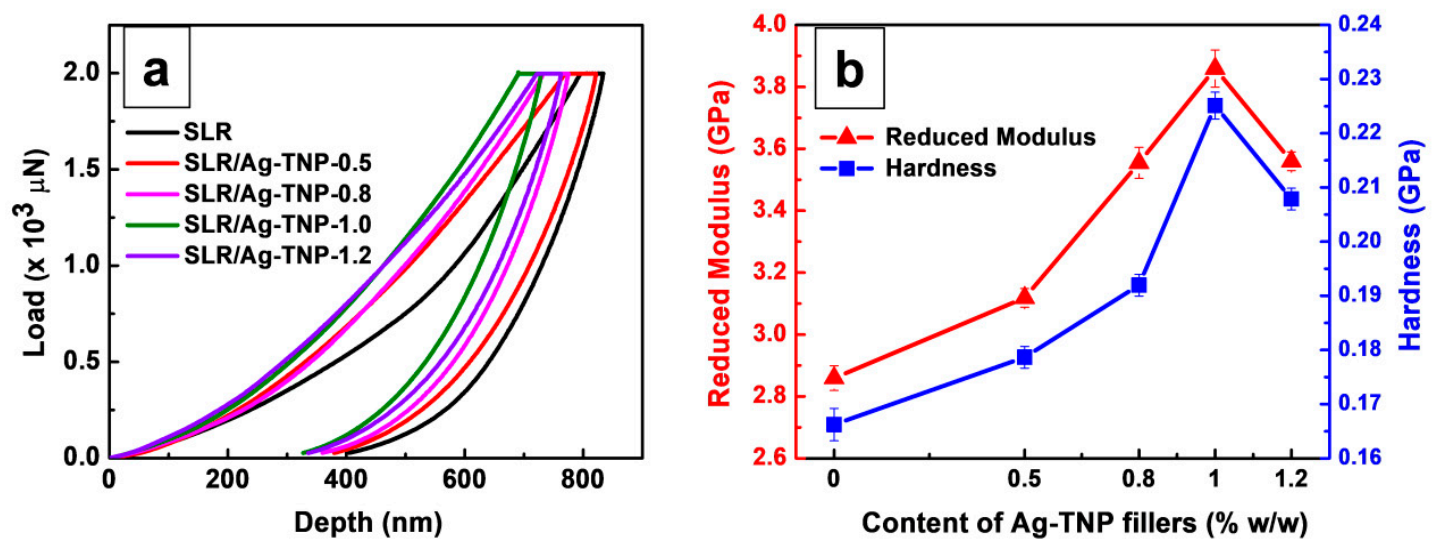

Figure 8. The nanoindentation analysis of neat SLR and SLR/Ag-TNP nanocomposites (a) the indentation load-depth curves for neat SLR and SLR/Ag-TNP nanocomposites with respect to different concentrations, (b) the observed variation of hardness (blue patterns) and reduced modulus (red patterns) of the SLR/Ag-TNP nanocomposites, where Ag-TNP content used as in $\% w / w$ of $0,0.5,0.8$, 1.0, and 1.2.

Table 3. Extracted results of pure SLR and SLR/AgTiO ${ }_{2}$ nanocomposites from the nanoindentation analysis.

\begin{tabular}{cccc}
\hline Sample & Indentation Depth $(\mathbf{n m})$ & $\begin{array}{c}\text { Reduced Modulus } \\
\mathbf{( G P a )}\end{array}$ & Hardness $(\mathrm{GPa})$ \\
\hline Neat SLR & 834.07 & $2.859 \pm 0.03$ & $0.1662 \pm 0.0030$ \\
SLR/Ag-TNP-0.5 & 822.16 & $3.118 \pm 0.05$ & $0.1786 \pm 0.0020$ \\
SLR/Ag-TNP-0.8 & 774.37 & $3.554 \pm 0.04$ & $0.1919 \pm 0.0020$ \\
SLR/Ag-TNP-1.0 & 728.52 & $3.859 \pm 0.06$ & $0.2251 \pm 0.0025$ \\
SLR/Ag-TNP-1.2 & 761.06 & $3.559 \pm 0.03$ & $0.2078 \pm 0.0020$ \\
\hline
\end{tabular}

The thermo-mechanical behaviors of the SLR/Ag-TNP and neat SLR nanocomposites were investigated with the help of Q800 TA instruments, and the observed results were discussed in this subsection. The DMA method was founded on an easy principle; when a model is subjected to a sinusoidal oscillating stress, its reply is a sinusoidal oscillation with parallel frequency furnishing the material staying within its elastic limits. When the material reacts to the employed oscillating stress entirely elastically, the responding strain wave is in-phase (elastic response or storage), while a viscous material responds with an out-of-phase strain wave (a viscous response or loss). Figure $9 \mathrm{a}, \mathrm{b}$ represent the deviations of storage modulus $\left(\mathrm{E}^{\prime}\right)$ and $\tan \delta$ as a function of temperature, respectively. In accordance with Figure $9 \mathrm{a}$, the storage modulus of $3 \mathrm{D}$ printed samples decreased slowly when temperature increased from $25^{\circ} \mathrm{C}$ to $180^{\circ} \mathrm{C}$. The storage modulus of the SLR/Ag-TNP nanocomposites was observed as increases with increasing Ag-TNP content with the SLR up to $1.0 \% w / w$. The increase in the storage modulus signifies the superior scattering and excellent interfacial interaction between the Ag-TNP and SLR matrix in the SLR/Ag-TNP nanocomposites [71]. In addition, Figure 9b demonstrates that, with the increasing nanofillers incorporation, the loss modulus increases gradually, with respect to the storage modulus and glass transition temperature. Later, a sudden decrement was noted when the nanofillers loading reaches over $1 \mathrm{wt} \%$. The loss modulus and storage modulus of SLR/Ag-TNP nanocomposites were decreased when the incorporation of Ag-TNP concentration was more than 1.0\% $w / w$, due to the elevated nanofillers loading causing reasonable agglomeration of Ag-TNP within the SLR matrix. The sample SLR/AgTNP-1.0 sustains the best storage modulus compared to all other samples with the highest value of 1953.1MPa, compared to a neat SLR value of 1495.2MPa, which was 
about $30.5 \%$ higher than the neat SLR. It ensured that the adding of Ag-TNP with SLR could enhance the storage modulus of 3D printed structure compared to neat SLR.
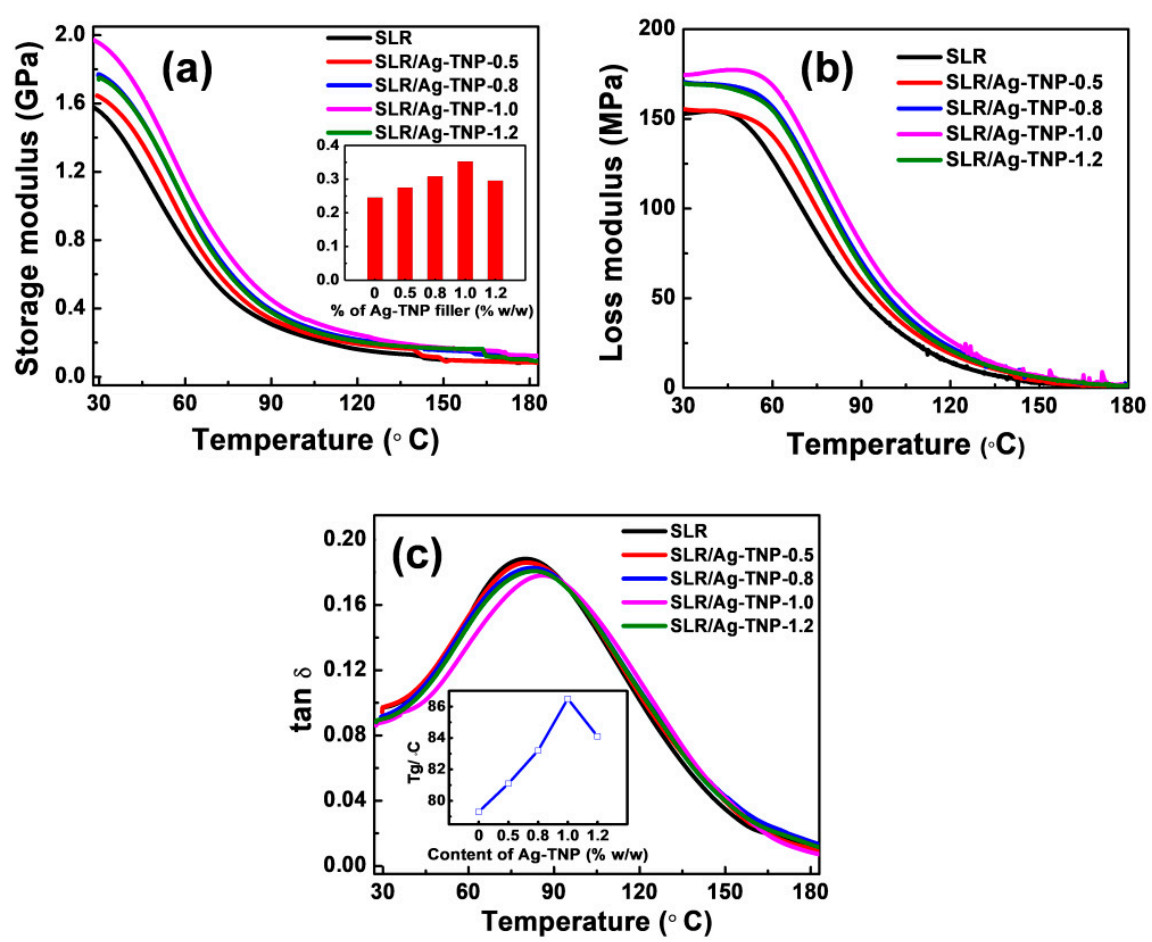

Figure 9. Thermo-mechanical analyses of neat SLR and SLR/Ag-TNP nanocomposites (a) comparative storage modulus, (b) comparative loss modulus curves, and (c) comparative $\tan \delta$ curves. The inserts in (a) and (c) express the dissimilarity of $\tan \delta$ and storage modulus of SLR/Ag-TNP nanocomposites with different loadings of Ag-TNP in the photo resin, respectively.

In addition to the storage modulus, Figure 9c shows the comparative study of $\tan \delta$ curves for the SLR/Ag-TNP and neat SLR nanocomposites. It was investigated from the $\tan \delta$ curves that the glass transition temperature $\left(\mathrm{T}_{g}\right)$ of the SLR/Ag-TNP-1.0 $\left(86.5^{\circ} \mathrm{C}\right)$ was the highest and could be improved by an elevated difference of $7.2^{\circ} \mathrm{C}$ compared to neat SLR $\left(79.3^{\circ} \mathrm{C}\right.$ ) (refer to the inset in Figure 9c). Beyond the $1.0 \mathrm{wt} \%$ loading concentration, the $\mathrm{T}_{g}$ value decreases due to higher agglomeration leading to the poor dispersion of Ag-TNP within the SLR matrix. The improved $\mathrm{T}_{g}$ could be interpreted as it ensures that the SLR/Ag-TNP-1.0 nanocomposites were thermally highly stable compared to all other samples. The optimized loading content of Ag-TNP expresses a good dispersion within the SLR matrix, and superior cross-linking density directs to a more significant interruption from polymer chain association so that the glass $\mathrm{T}_{g}$ progress was noted at upper temperatures for SLR/Ag-TNP-1.0 nanocomposites. The detailed observed values of DMA analysis were given with Table 4.

Table 4. The storage modulus and $\tan \delta$ values of neat SLR and SLR/Ag-TNP nanocomposites.

\begin{tabular}{ccccc}
\hline \multirow{2}{*}{ Sample } & \multicolumn{2}{c}{ Storage Modulus (MPa) } & \multirow{2}{*}{$\tan \delta$ Peak Height } & \multirow{2}{*}{$\mathbf{T}_{\boldsymbol{g}}\left({ }^{\circ} \mathbf{C}\right)$} \\
\cline { 2 - 3 } & $\mathbf{3 0}{ }^{\circ} \mathbf{C}$ & $\mathbf{1 0 0}{ }^{\circ} \mathbf{C}$ & & \\
\hline Neat SLR & 1495.2 & 245.1 & 0.188 & 79.3 \\
SLR/Ag-TNP-0.5 & 1637.4 & 264.8 & 0.185 & 81.1 \\
SLR/Ag-TNP-0.8 & 1769.9 & 308.9 & 0.182 & 83.2 \\
SLR/Ag-TNP-1.0 & 1953.1 & 350.5 & 0.177 & 86.5 \\
SLR/Ag-TNP-1.2 & 1751.1 & 295.5 & 0.179 & 84.1 \\
\hline
\end{tabular}




\subsubsection{Thermal Properties}

The thermogravimetric analysis of neat SLR and SLR/Ag-TNP nanocomposites was analyzed, and the resulted graph, as shown in Figure 10a. In conformity with Figure 12a and Table 5, in which the residual weight of pristine SLR was noted as the lowest among all the TGA tested samples, and an increasing trend of residual char was noted with the loading percentage of Ag-TNP into the SLR matrix. The residual char weight $\%$ in the SLR/Ag-TNP nanocomposites was considerably high compared to pure SLR (5.86), which was showing that the relatively high thermal stability of the SLR/Ag-TNP nanocomposites at high temperatures (for the SLR/Ag-TNP-1.0 sample, the residue weight \% was noted as 8.01). However, the loading concentration of Ag-TNP increases beyond the level of $1.0 \% w / w$, and the sudden decrement of residual char value was noted as a reason for these phenomena was maybe the higher concentration of Ag-TNP could make possible agglomeration within the SLR matrix, which leads to poor dispersion and weakening the thermal stability of SLR/Ag-TNP nanocomposites. The above-mentioned interpretation proposes that the exceptional thermal stability with a lower decomposition rate has been found in the sample SLR/Ag-TNP-1.0. In addition, the value of the mean temperature of the squalor $\left(\mathrm{T}_{-50 \%}\right.$, temperature) and the residue char value at $800{ }^{\circ} \mathrm{C}$ were abridged in Table 5. For the neat SLR nanocomposites, the $\mathrm{T}_{-50 \%}$ was noted as 424.1 , and it was significantly increased for the samples of SLR/Ag-TNP nanocomposites. The enhancement of thermal stability can be reorganized by taking into account of the tears, movement, and thermal disintegration of the polymer manacles. With the strong interactions between the incorporated Ag-TNP and SLR matrix, the movements of the polymer chains were partial for the period of the thermal degradation process, which was significantly responsible for the progress in thermal enhancement [72].
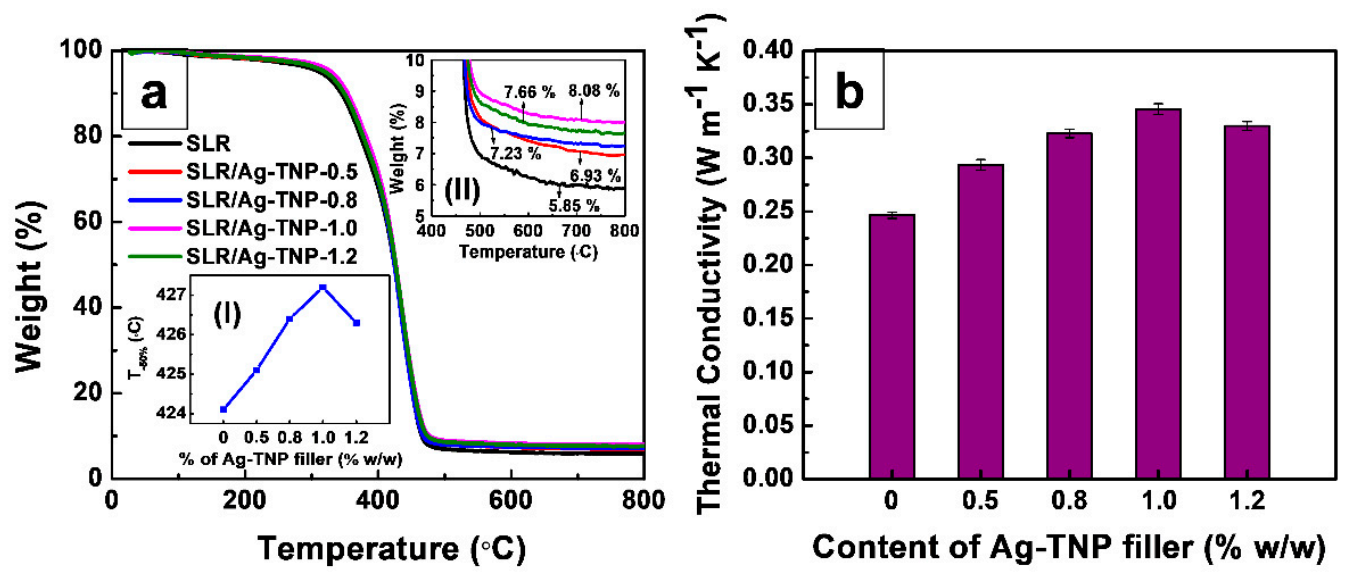

Figure 10. Thermal properties analysis of neat SLR and SLR/nanofillers nanocomposites. (a) comparative thermogravimetric analysis (TGA) curves of neat SLR and SLR/nanofillers nanocomposites with different concentrations, and (b) comparative thermal conductivity analysis of neat SLR and SLR/nanofillers nanocomposites with respect to various concentrations. The insert graphs of (I) and (II) in (a) illustrates the residual char $\mathrm{w} t \%$ and variation of $\mathrm{T}_{-50 \%}$ as a function of different $\% w / w$ of Ag-TNP, respectively.

Table 5. Results of TGA and Thermal conductivity of SLR/Ag-TNP and neat SLR nanocomposites.

\begin{tabular}{|c|c|c|c|}
\hline Sample & $\mathrm{T}_{-50 \%}\left({ }^{\circ} \mathrm{C}\right)$ & Residual Char (wt\%) & Thermal Conductivity $\left(\mathrm{W} \cdot \mathrm{m}^{-1} \cdot \mathrm{K}^{-1}\right)$ \\
\hline Neat SLR & 424.1 & 5.86 & $0.2465 \pm 0.003$ \\
\hline SLR/Ag-TNP-0.5 & 425.1 & 6.93 & $0.2934 \pm 0.005$ \\
\hline SLR/Ag-TNP-0.8 & 426.4 & 7.24 & $0.3228 \pm 0.004$ \\
\hline SLR/Ag-TNP-1.0 & 427.2 & 8.01 & $0.3456 \pm 0.005$ \\
\hline SLR/Ag-TNP-1.2 & 426.3 & 7.63 & $0.3298 \pm 0.004$ \\
\hline
\end{tabular}


Figure $10 \mathrm{~b}$ represents the thermal conductivity measurements of the neat SLR and SLR/Ag-TNP nanocomposites. From Figure $10 \mathbf{b}$ and Table 5, it was investigated that the thermal conductivity of the SLR/Ag-TNP nanocomposites considerably increases when the loading percentage of Ag-TNP increases with the SLR matrix. The average thermal conductivity value of the neat SLR was noted as $0.2465\left(\mathrm{~W} \cdot \mathrm{m}^{-1} \cdot \mathrm{K}^{-1}\right)$ and the thermal conductivity of the SLR/Ag-TNP nanocomposites increasing with respect to the increases in the $\% w / w$ of Ag-TNP, as it reaches $1.0 \% w / w$ of Ag-TNP nanoparticles with a value of $0.3456\left(\mathrm{~W} \cdot \mathrm{m}^{-1} \cdot \mathrm{K}^{-1}\right)(40.2 \%$ of increment in the thermal conductivity more than the neat SLR). When increasing the loading percentage of Ag-TNP in excess of $1.0 \% w / w$, within the SLR matrix, the deprived thermal conductivity was noted. The thermal conductivity initially increased and was a decreasing trend with the incorporation of Ag-TNP, which was due to the elevated loading of nanofillers possibly causing agglomeration, which leads to poor dispersion within the polymer matrix and lessens the thermal conductivity. Moreover, silver was considered as one of the excellent thermal conductors among the metals. Here, the enhancement of thermal conductivity may be due to the silver decorated TNP attaining very good dispersion within the SLR matrix at lower loading concentration, which could possibly enhance the thermal conductivity of SLR/Ag-TNP nanocomposites [73]. To study the thermal conductivity significance of our research work, the observed thermal conductivity values were compared with other reported photocurable resin/nanocomposites thermal conductivity values. The comparative thermal conductivity was displayed in Table 6.

Table 6. The photocurable resin/nanofillers thermal conductivity comparison study with different nanocomposites.

\begin{tabular}{|c|c|c|}
\hline Nanocomposites & Thermal Conductivity $\left(\mathrm{W} \cdot \mathrm{m}^{-1} \cdot \mathrm{K}^{-1}\right)$ & References \\
\hline SLR/Ag-TNP-1.0 & 0.34 & This work \\
\hline ( SLR/ANT800 & 0.29 & [74] \\
\hline${ }^{@}$ MPTS/hBN-5\% & 0.30 & [75] \\
\hline \# SU-8/FGS-2\% & 0.36 & [76] \\
\hline$\$$ CE/BNNT-1.5\% & 0.40 & [77] \\
\hline \& UV curable polyacrylate/PGN15 & 0.29 & [78] \\
\hline * UV curable polyacrylate/PGN25 & 0.27 & [78] \\
\hline
\end{tabular}

\footnotetext{
(B) Stereolithography resin incorporated with $800{ }^{\circ} \mathrm{C}$ annealed anataseTiO ${ }_{2}$ nanoparticles. (응 Photocurable acrylic-based photopolymer composites with $5 \mathrm{wt} \%$ of hexagonal boron nitride (hBN) modified with $\gamma$-Methacryloxypropyltrimethoxysilane. \# Photocurable SU-8 epoxy-based composites containing $2 \mathrm{wt} \%$ functionalized graphene sheets (FGS). \$ Photo curable epoxy-based composites which contain (3,4-Epoxy cyclohexylmethyl-3,4-epoxycyclohexane carboxylate (CE) with $1.5 \mathrm{wt} \%$ of Boron Nitride nanotubes (BNNTs). \& UV-curable polyacrylate incorporated with $15 \mathrm{~nm}$ size gold nanocomposites (PGN15). * UV-curable polyacrylate incorporated with $25 \mathrm{~nm}$ size gold nanocomposites (PGN25).
}

The kinetic study of photo-polymerization reaction of both neat SLR resin and Ag-TNP nanofillers incorporated SLR nanocomposites analyzed with the assistance of Real-Time Fourier transform infrared spectra (RT-FTIR), and the observed results are presented in Figure 11. The photopolymerization kinetics was resolved by the decline of absorption peak intensity around $809-811 \mathrm{~cm}^{-1}$ from the FTIR analysis, which was attributed to the twisting vibration mode of double-bond in an acrylic group [79]. The degree of conversion (DC) of a double-bond was calculated from Equation (3) [80,81]:

$$
\% \text { Conversion }=\frac{\mathrm{A}_{0}-\mathrm{A}_{\mathrm{t}}}{\mathrm{A}_{0}} \times 100 \%
$$

where $A_{0}$ is the initial peak area before the irradiation at $809.5 \mathrm{~cm}^{-1}$, while $A_{t}$ is the peak area at irradiation time $t$ at $809.5 \mathrm{~cm}^{-1}$ during the polymerization, respectively. 

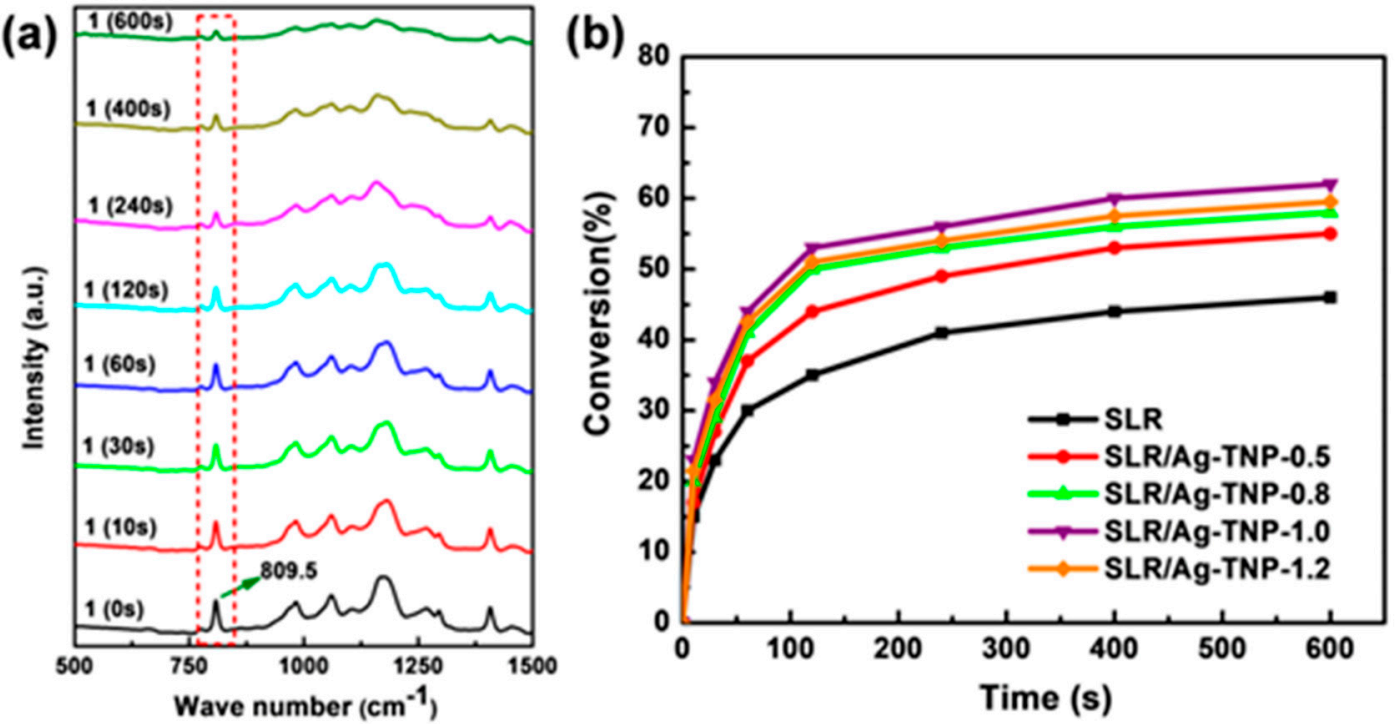

Figure 11. (a) a real-time FTIR analysis of photopolymerization of SLR/Ag-TNP-1 nanocomposite in different periods of time intervals starting from $0 \mathrm{~s}$ to $600 \mathrm{~s}$ under the UV irradiation power of $32 \mathrm{~mW} / \mathrm{cm}^{2}$, (b) percentage conversion graph of neat SLR and SLR/Ag-TNP nanocomposites.

The analysis was executed on the basis of different time intervals to comprehend the photopolymerization progression. Initially, the uncured vat slurry was examined by FTIR, followed by UV curing with an irradiation power of $32 \mathrm{~mW} / \mathrm{cm}^{2}$ at different time intervals such as $10 \mathrm{~s}, 30 \mathrm{~s}, 60 \mathrm{~s}$, $120 \mathrm{~s}, 240 \mathrm{~s}, 400 \mathrm{~s}$, and $600 \mathrm{~s}$. The neat SLR and SLR/Ag-TNP-1 slurry analysis is presented in Figure 11a, and all other SLR/nanofillers analyses such as SLR/Ag-TNP-0.5, SLR/Ag-TNP-0.8, and SLR/Ag-TNP-1.2 are displayed in Supplementary Figure S5. The analysis was employed to determine the absorbance intensity of the peak at $809.5 \mathrm{~cm}^{-1}$, which is related to acrylate double bond. From the FTIR analysis, the percentage conversion versus time curves was plotted to understand the photopolymerization reactions based on the double bond $(\mathrm{C}=\mathrm{C})$ conversion ratio taking place in different time periods. Figure $11 \mathrm{~b}$ shows that the conversion rates of the photopolymerization reactions were enhanced by the addition of nanofillers content. Figure $11 \mathrm{~b}$ expresses that the SLR/Ag-TNP-1 nanocomposite showed a better $\mathrm{C}=\mathrm{C}$ conversion rate of photopolymerization among all other SLR/nanofillers' composites. The percentage conversion of SLR/Ag-TNP-1 was reached to $62.2 \%$ at the 600 seconds, where percent conversion of SLR was only $45.8 \%$. In addition, to investigate the effect of radiation power on the photopolymerization kinetics, as prepared SLR/Ag-TNP-1\% nanocomposites have been taken to perform under the different UV power intensities. The recorded RT-FTIR polymerization profiles of the sample with different power densities of UV-irradiation at different time intervals are illustrated in the supplementary Figure S6. The analysis was executed on the basis of different time intervals to realize the photopolymerization evolution. Primarily, the uncured SLR/Ag-TNP-1 slurry was examined by FTIR, followed by UV curing with an irradiation power of $24 \mathrm{~mW} / \mathrm{cm}^{2}$ at different time intervals such as $10 \mathrm{~s}, 30 \mathrm{~s}, 60 \mathrm{~s}, 120 \mathrm{~s}, 240 \mathrm{~s}, 400 \mathrm{~s}$, and $600 \mathrm{~s}$. The same procedure carried out for SLR/Ag-TNP-1 with different power densities of UV irradiation of $28 \mathrm{~mW} / \mathrm{cm}^{2}$ and $32 \mathrm{~mW} / \mathrm{cm}^{2}$ in the above-mentioned time intervals. The percentage conversions of SLR/Ag-TNP-1 at 600s in the different UV exposure power densities of $24 \mathrm{~mW} / \mathrm{cm}^{2}, 28 \mathrm{~mW} / \mathrm{cm}^{2}$ and $32 \mathrm{~mW} / \mathrm{cm}^{2}$ are $55.8 \%, 59.1 \%$, and $62.2 \%$, respectively.

\subsection{Thermal and Mechanical Reinforcement Mechanism of SLR/Ag-TNP 3D Printed Samples}

Figure 12 demonstrates that the energy or intensity of UV light decreases with respect to its penetration depth increasing through the photo resin nanocomposites. The incorporated low bandgap semiconducting nanoparticles (here, Ag-TNP) can able to generate more electron-hole pairs compared to high bandgap semiconducting NPs (here, $\mathrm{TiO}_{2}$ ) at deep penetration depth, where the energy of UV 
light was less. For the better understandings, we have performed the photopolymerization kinetic study of SLR/TNP-1 and SLR/Ag-TNP-1 nanocomposites via real-time FTIR study and the \% conversion of $\mathrm{C}=\mathrm{C}$ was calculated from the analysis; the resulting graphs were displayed in the supplementary Figure S7. Thus, Ag-TNP can induce the photopolymerization via fast and strong cross-linking with the SLA resin matrix, which leads to better improvement over mechanical and thermal properties of the SLR/nanofillers 3D printed polymer nanocomposites. The semiconducting nanoparticles can able to induce photopolymerization by the process of possible creation of electron hole pair in the presence of UV light, which leads to enhancing the thermal and mechanical properties of a polymer matrix $[82,83]$.

(a)

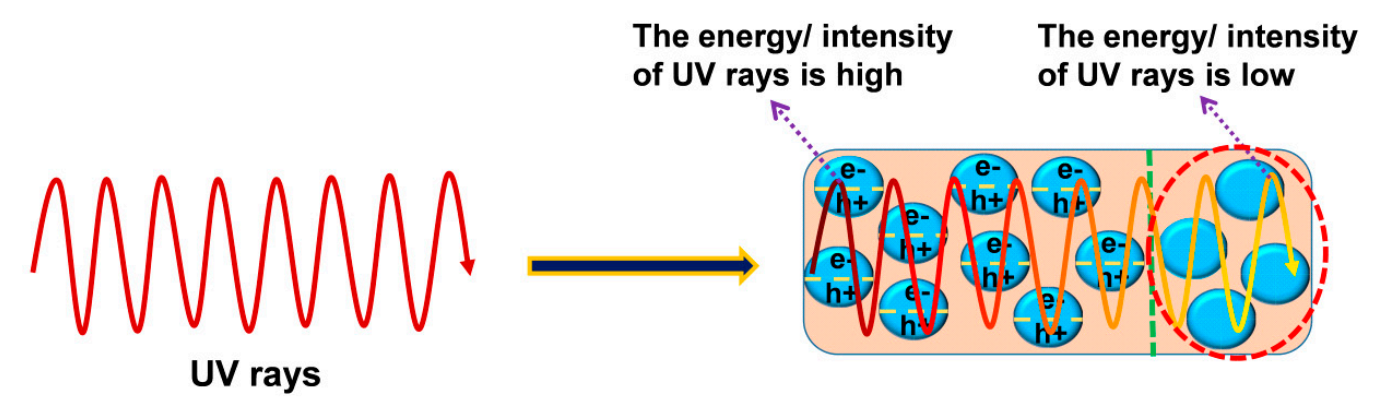

(b)
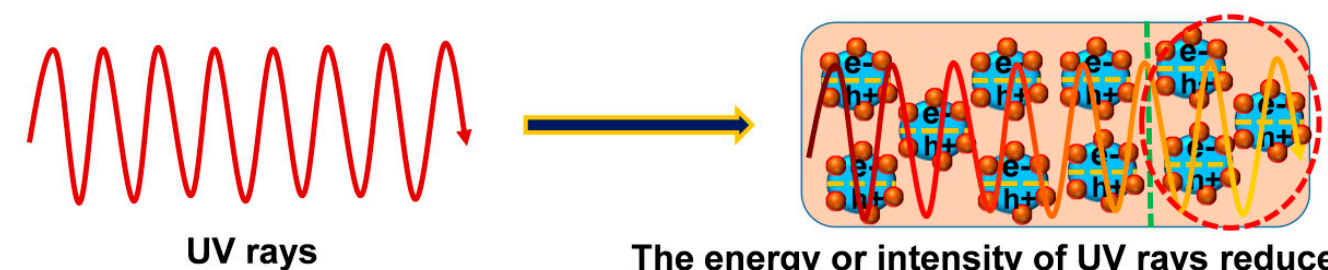

The energy or intensity of UV rays reduces when it moves through the resin media

TNP - Ag-TNP

Figure 12. The proposed induced photopolymerization mechanism of SLR/nanofillers schematic illustration of UV light penetration through the (a) SLR/high energy bandgap semiconducting NPs (e.g., $\mathrm{TiO}_{2}$ ) (the dotted red circles represents there is no possible electron hole pairs generation when the UV intensity decreases), and (b) SLR/low energy bandgap semiconducting NPs (e.g., Ag-TNP) (the dotted red highlights demonstrates that, the successful electron-hole pairs formation even at lower intensity of UV lights). The energy/intensity of UV rays reduces (the red color lines indicate higher intensity and pale yellow color lines indicates lower intensity) when it undergoes deep penetration through the resin composites.

The UV rays on the surface of semiconducting Ag-TNP can experience a photo-excitation which causes the multiplication of electrons in conduction band (CB) and holes in valence band (VB) as presented in Equation (4) [84]:

$$
\mathrm{Ag}-\mathrm{TNP}+\mathrm{h} v \rightarrow \operatorname{Ag}-\mathrm{TNP}\left(\mathrm{e}^{-} \mathrm{CB}+\mathrm{h}^{+}{ }_{\mathrm{VB}}\right) .
$$

The as-developed holes in VB can oxidize acrylic monomers extending to the production of free radicals (refer to the Equation (5)), which can encourage the initiation for polymerization chemical reaction (refer to the Equation (6)):

$$
\begin{gathered}
\mathrm{h}^{+} \mathrm{VB}+\mathrm{MA} \rightarrow \mathrm{M} \mathrm{A}^{\bullet}+\mathrm{H}^{+} \\
\mathrm{M} \mathrm{A}^{\bullet}+\mathrm{MA} \rightarrow \mathrm{PR}
\end{gathered}
$$


In addition, the photo-reduction reaction by $\mathrm{CB}$ electrons experiences the reaction correspondingly:

$$
\begin{gathered}
\mathrm{e}^{-} \text {Св }+\mathrm{MA} \rightarrow \mathrm{MA}^{\bullet-} \\
\mathrm{MA}^{\bullet-}+\mathrm{H}^{+} \rightarrow \mathrm{HMA}^{\bullet}
\end{gathered}
$$

The recipe of electrons in $\mathrm{CB}$ with protons induces the establishment of atomic hydrogen compiled by $\mathrm{H} \mathrm{MA}^{\bullet}$ radicals, which aids with starting the polymerization process:

$$
\begin{gathered}
\mathrm{e}^{-} \mathrm{CB}+\mathrm{H}^{+} \rightarrow \mathrm{H}^{\bullet} \\
\mathrm{MA}+\mathrm{H}^{\bullet} \rightarrow \mathrm{H} \mathrm{MA}^{\bullet}
\end{gathered}
$$

where, MA, $\mathrm{MA}^{\bullet}$, and PR symbolizes, the acrylate based monomer, monomer radical and polymer, respectively.

With regard to the semiconducting behaviour of the incorporated metal-metal oxide nanofillers (Ag-TNP), the photo-absorption process of Ag-TNP hybrids is able to generate valence band holes and conduction band electrons on the surface of Ag-TNP upon UV irradiation [52]. However, the electrons and holes generated from the Ag-TNP nanoparticles assistance with the formation of monomer radicals, which can react further with the monomer and thereby initiate polymerization chains, but the propagation of polymer chain occurs due to the monomer radicals. Hence, this polymer reaction was considered as free radical photopolymerization [85]. Herein, the photopolymerization can occur in three routes. Firstly, holes, generated in a valence band can oxidize organic molecules such as acrylic monomer leading to the formation of monomer radical (refer to Equation (5)), which can react further with the monomer and thereby initiate polymerization chains (shown in Equation (6)). Secondly, photoreduction by conduction band electrons can take place at the same time and form a negative charged monomer radical (Equation (7) and Equation (8)). The proton created as a by-product from the first route, which can react with the negative charged monomer radical, can form $\mathrm{H} \mathrm{MA}{ }^{\bullet}$ radicals (Equation (8)), which can react further with the monomer to form the polymer chains. Thirdly, the interaction of conduction band electrons with protons occurs, leading to atomic hydrogen formation (Equation (9)). The latter attack to the monomer can form HM radicals (Equation (10)) capable of initiating polymerization of the acrylic monomer [86].

It was affirmed by the mechanical and thermal analysis of Ag-TNP incorporated 3D printed samples, in which the sample SLR/Ag-TNP-1.0 exhibited a prominent improvement of thermal and mechanical properties. The splendid property enrichment was accomplished for SLR/Ag-TNP-1.0, entailing that the introduced Ag-TNP-1.0 having an extremely crystalline anatase phase and the scummiest energy bandgap can be proficient to engender a quick massive figure of electron-hole pairs, which leads to the burly cross-linking among monomers and oligomers in SLR/Ag-TNP nanocomposites.

\section{Conclusions}

The semiconducting low energy bandgap Ag-TNP was synthesized through the sol-gel method and utilized as nanofillers in the stereolithography resin matrix to enhance the thermal and mechanical properties of 3D printing samples. The research study shows that the introduction of Ag-TNP in the SLR matrix can extensively enhance the mechanical and thermal behaviors of 3D printed samples. The mechanical properties of the 3D printed samples were increasing remarkably when the Ag-TNP was added into the SLR up to $1.0 \% w / w$ and decreased when the addition went beyond $1.0 \% w / w$ due to the agglomeration of higher concentration of nanoparticles causing the poor dispersion and improper cross-linking density. In addition, the thermal conductivity and thermal stability of the 3D printed samples of SLR/Ag-TNP nanocomposites were increased with the increasing loading percentage of Ag-TNP with the SLR matrix. This study presents a promising result and gives an instructive role to manufacture of stereolithography 3D printing parts by using Ag-TNP dispersed in the SLR matrix with excellent performance in the mechanical and thermal properties, which accelerates 
the expansion and sensible function of SLR/Ag-TNP nanocomposites and widens the applications of additive manufacturing technology.

Supplementary Materials: The following are available online at http://www.mdpi.com/2079-4991/10/2/217/s1, Figure S1: A detailed schematic illustrates of synthesis route of Ag-TNP. Figure S2: The step by step detailed preparation route of SLR/Ag-TNP nanocomposites. Figure S3: The digital image of the Dream 3D-C200 SLA 3D printing device, which was utilized for this research work. Figure S4: XPS spectrum analysis of as-prepared $\mathrm{TiO}_{2}$, and Ag/TNP (a) survey spectrum (black spectrum represents $\mathrm{TiO}_{2}$ and red spectrum represents Ag-TNP), (b) Deconvoluted XPS spectra of Ti, and (c) Deconvoluted XPS spectra of Ag, (c) Deconvoluted XPS spectra of O. Figure S5: A real-time FTIR analysis of photopolymerization of (a) neat SLR, (b) SLR/Ag-TNP-0.5, (c) SLR/Ag-TNP-0.8, and (d) SLR/Ag-TNP-1.2, nanocomposites in different periods of time intervals starting from $0 \mathrm{~s}$ to $600 \mathrm{~s}$ under the UV irradiation power of $32 \mathrm{~mW} / \mathrm{cm}^{2}$. Figure S6: (a) percentage conversion graph of SLR/Ag-TNP-1 nanocomposite in different power densities of UV-irradiation monitored by RT-FTIR. (b), (c), and (d) are real-time FTIR analysis of photopolymerization of SLR/Ag-TNP-1 nanocomposites in different periods of time intervals starting from $0 \mathrm{~s}$ to $600 \mathrm{~s}$ under UV irradiation power densities of $24 \mathrm{~mW} / \mathrm{cm}^{2}, 28 \mathrm{~mW} / \mathrm{cm}^{2}$ and 32 $\mathrm{mW} / \mathrm{cm}^{2}$, respectively. Figure S7: (a) real-time FTIR analysis of SLR/TNP-1 nanocomposite and (b) percentage conversion graph of photopolymerization of SLR/TNP-1 nanocomposite (black line) and SLR/Ag-TNP-1 (red line) nanocomposite, under the UV irradiation power of $32 \mathrm{~mW} / \mathrm{cm}^{2}$ in different periods of time intervals starting from $0 \mathrm{~s}$ to $600 \mathrm{~s}$. Table S1: The composition of mixture used for SLA photoresin preparation.

Author Contributions: S.M. and L.W. planned and designed the project, and L.W. supervised the work. S.M. has performed synthesis of nanocomposites, the 3D printing process, and analysis. D.D. and M.B.K. contributed to data interpretation and writing of this manuscript. N.D., T.S., S.P., and J.W. assisted with the analysis of various characterization technologies. All authors discussed the results and commented on the manuscript. All authors have read and agreed to the published version of the manuscript

Funding: This work was financially supported by the State's Key Project of Research and Development Plan (Grant No.: 2016YFB1100900), the Regional Key Program of Science and Technology Service Network Initiative from Chinese Academy of Sciences, the Key Research Project of Jiangxi Province (Grant No.: 20192ACB80002), the Fund of the National Engineering and Research Center for Commercial Aircraft Manufacturing, the STS Project of Fujian-CAS (Grant No.: 2017T3005, 2019T3013, 2019T3016 and 2019T3018), the Fund of National Engineering Research Center for Optoelectronic Crystalline Materials, and "One-Three-Five" Strategic Planning Project of Haixi Institute of Chinese Academy of Sciences (CXZX-2017-P04).

Acknowledgments: We acknowledge the University of Chinese Academy of Sciences for providing China Scholarship Council (CSC) Postgraduate Scholarship for International Students.

Conflicts of Interest: The authors declare no conflict of interest.

\section{References}

1. Gou, M.; Qu, X.; Zhu, W.; Xiang, M.; Yang, J.; Zhang, K.; Wei, Y.; Chen, S. Bio-inspired Detoxification Using 3D-Printed Hydrogel Nanocomposites. Nat. Commun. 2014, 8, 3774. [CrossRef] [PubMed]

2. Van der Valk, D.C.; van der Ven, C.F.T.; Blaser, M.C.; Grolman, J.M.; Wu, P.J.; Fenton, O.S.; Lee, L.H.; Tibbitt, M.W.; Andresen, J.L.; Wen, J.R.; et al. Engineering a 3D-bioprinted model of human heart valve disease using nanoindentation-based biomechanics. Nanomaterials 2018, 8, 296. [CrossRef] [PubMed]

3. Patrick, J.F.; Krull, B.P.; Garg, M.; Mangun, C.L.; Moore, J.S.; Sottos, N.R.; White, S.R. Robust sacrificial polymer templates for 3D interconnected microvasculature in fiber-reinforced composites. Compos. Pt. A Appl. Sci. Manuf. 2017, 100, 361-370. [CrossRef]

4. Kamat, A.M.; Pei, Y.; Kottapalli, A.G.P. Bioinspired Cilia Sensors with Graphene Sensing Elements Fabricated Using 3D Printing and Casting. Nanomaterials 2019, 9, 954. [CrossRef] [PubMed]

5. Jiao, L.; Chua, Z.Y.; Moon, S.K.; Song, J.; Bi, G.; Zheng, H.; Lee, B.; Koo, J. Laser-induced graphene on additive manufacturing parts. Nanomaterials 2019, 9, 90. [CrossRef] [PubMed]

6. Cai, S.; Shi, H.; Li, G.; Xue, Q.; Zhao, L.; Wang, F.; Hu, B. 3D-printed concentration-controlled microfluidic chip with diffusion mixing pattern for the synthesis of alginate drug delivery microgels. Nanomaterials 2019, 9, 1451. [CrossRef]

7. Palmero, E.M.; Casaleiz, D.; de Vicente, J.; Hernández-Vicen, J.; López-Vidal, S.; Ramiro, E.; Bollero, A. Composites based on metallic particles and tuned filling factor for 3D-printing by Fused Deposition Modeling. Compos. Pt. A Appl. Sci. Manuf. 2019, 124, 105497. [CrossRef] 
8. Sugiyama, K.; Matsuzaki, R.; Ueda, M.; Todoroki, A.; Hirano, Y. 3D printing of composite sandwich structures using continuous carbon fiber and fiber tension. Compos. Pt. A Appl. Sci. Manuf. 2018, 113, 114-121. [CrossRef]

9. Ligon, S.C.; Liska, R.; Stampfl, J.; Gurr, M.; Mülhaupt, R. Polymers for 3D printing and customized additive manufacturing. Chem. Rev. 2017, 117, 10212-10290. [CrossRef]

10. Li, Y.; Feng, Z.; Huang, L.; Essa, K.; Bilotti, E.; Zhang, H.; Peijs, T.; Hao, L. Additive manufacturing high performance graphene-based composites: A review. Compos. Pt. A Appl. Sci. Manuf. 2019, 124, 105483. [CrossRef]

11. Zhang, F.; Li, C.; Wang, Z.; Zhang, J.; Wang, Y. Multimaterial 3D Printing for Arbitrary Distribution with Nanoscale Resolution. Nanomaterials 2019, 9, 1108. [CrossRef] [PubMed]

12. Stansbury, J.W.; Idacavage, M.J. 3D printing with polymers: Challenges among expanding options and opportunities. Dent. Mater. 2016, 32, 54-64. [CrossRef] [PubMed]

13. Bártolo, P.J. Stereolithography: Materials, Processes and Applications, 1st ed.; Springer: New York, NY, USA, 2011; pp. 37-52.

14. Fantino, E.; Vitale, A.; Quaglio, M.; Cocuzza, M.; Pirri, C.F.; Bongiovanni, R. Blue and UV combined photolithographic polymerization for the patterning of thick structures. Chem. Eng. J. 2015, 267, 65-72. [CrossRef]

15. Fouassier, J.P.; Allonas, X.; Burget, D. Photopolymerization reactions under visible lights: Principle, mechanisms and examples of applications. Prog. Org. Coat. 2003, 47, 16-36. [CrossRef]

16. Purtov, J.; Rogin, P.; Verch, A.; Johansen, V.E. Nanopillar Di ff raction Gratings by Two-Photon Lithography. Nanomaterials 2019, 9, 1495. [CrossRef] [PubMed]

17. Shao, J.; Huang, Y.; Fan, Q. Visible light initiating systems for photopolymerization: Status, development and challenges. Polym. Chem. 2014, 5, 4195-4210. [CrossRef]

18. Crivello, J.V.; Reichmanis, E. Photopolymer materials and processes for advanced technologies. Chem. Mater. 2013, 26, 533-548. [CrossRef]

19. Liu, Y.; Campbell, J.H.; Stein, O.; Jiang, L.; Hund, J.; Lu, Y. Deformation behavior of foam laser targets fabricated by two-photon polymerization. Nanomaterials 2018, 8, 498. [CrossRef]

20. Hu, L.; Shi, W. UV-cured organic-inorganic hybrid nanocomposite initiated by trimethoxysilane-modified fragmental photoinitiator. Compos. Pt. A Appl. Sci. Manuf. 2011, 42, 631-638. [CrossRef]

21. Nguyen, L.H.; Straub, M.; Gu, M. Acrylate-based photopolymer for two-photon micro-fabrication and photonic applications. Adv. Funct. Mater. 2005, 15, 209-216. [CrossRef]

22. Wang, P.H.; Wang, T.L.; Lin, W.C.; Lin, H.Y.; Lee, M.H.; Yang, C.H. Crosslinked polymer ionic liquid/ionic liquid blends prepared by photopolymerization as solid-state electrolytes in supercapacitors. Nanomaterials 2018, 8, 225. [CrossRef] [PubMed]

23. Chen, M.; Zhong, M.; Johnson, J.A. Light-controlled radical polymerization: Mechanisms, methods, and applications. Chem. Rev. 2016, 116, 10167-10211. [CrossRef] [PubMed]

24. Song, S.Y.; Park, M.S.; Lee, J.W.; Yun, J.S. A study on the rheological and mechanical properties of photo-curable ceramic/polymer composites with different silane coupling agents for SLA 3D printing technology. Nanomaterials 2018, 8, 93. [CrossRef] [PubMed]

25. Chiappone, A.; Roppolo, I.; Naretto, E.; Fantino, E.; Calignano, F.; Sangermano, M.; Pirri, F. Study of graphene oxide-based 3D printable composites: Effect of the in situ reduction. Compos. Pt. B Eng. 2017, 124, 9-15. [CrossRef]

26. Manapat, J.Z.; Mangadlao, J.D.; Tiu, B.D.; Tritchler, G.C.; Advincula, R.C. High-strength Stereolithographic 3D printed nanocomposites: Graphene oxide meta-stability. ACS Appl. Mater. Interfaces 2017, 9, 10085-10093. [CrossRef]

27. Gardner, J.M.; Sauti, G.; Kim, J.W.; Cano, R.J.; Wincheski, R.A.; Stelter, C.J.; Grimsley, B.W.; Working, D.C.; Siochi, E.J. 3-D printing of multifunctional carbon nano-tube yarn reinforced components. Addit. Manuf. 2016, 12, 38-44.

28. Chen, S.G.; Yang, J.; Jia, Y.-G.; Lu, B.; Ren, L. $\mathrm{TiO}_{2}$ and PEEK Reinforced 3D Printing PMMA Composite Resin for Dental Denture Base Applications. Nanomaterials 2019, 9, 1049. [CrossRef]

29. Liu, T.; Tian, X.; Zhang, M.; Abliz, D.; Li, D.; Ziegmann, G. Interfacial performance and fracture patterns of 3D printed continuous carbon fiber with sizing reinforced PA6 composites. Compos. Pt. A Appl. Sci. Manuf. 2018, 114, 368-376. [CrossRef] 
30. Dalaq, A.S.; Abueidda, D.W.; Al-Rub, R.K.A. Mechanical properties of 3D printed interpenetrating phase composites with novel architectured 3D solid-sheet reinforcements. Compos. Pt. A Appl. Sci. Manuf. 2016, 84, 266-280. [CrossRef]

31. Cano, M.; Khan, U.; Sainsbury, T.; O’Neill, A.; Wang, Z.; McGovern, I.T.; Maser, W.K.; Benito, A.M.; Coleman, J.N. Improving the mechanical properties of graphene oxide based materials by covalent attachment of polymer chains. Carbon 2013, 52, 363-371. [CrossRef]

32. Liu, J.; Li, W.; Guo, Y.; Zhang, H.; Zhang, Z. Improved thermal conductivity of thermoplastic polyurethane via aligned boron nitride platelets assisted by 3D printing. Compos. Pt. A Appl. Sci. Manuf. 2019, 120, 140-146. [CrossRef]

33. Benad, A.; Jürries, F.; Vetter, B.; Klemmed, B.; Hübner, R.; Leyens, C.; Eychmüller, A. Mechanical properties of metal oxide aerogels. Chem. Mater. 2017, 30, 145-152. [CrossRef]

34. Jia, Q.; Ghoshal, S.; Li, J.; Liang, W.; Meng, G.; Che, H.; Zhang, S.; Ma, Z.F.; Mukerjee, S. Metal and metal oxide interactions and their catalytic consequences for oxygen reduction reaction. J. Am. Chem. Soc. 2017, 139, 7893-7903. [CrossRef] [PubMed]

35. Li, S.S.; Chen, C.W. Polymer-metal-oxide hybrid solar cells. J. Mater. Chem. A 2013, 1, $10574-10591$. [CrossRef]

36. Yang, Y.; Zhang, C.; Hu, Z. Impact of metallic and metal oxide nanoparticles on wastewater treatment and anaerobic digestion. Environ. Sci. Process. Impacts 2012, 15, 39-48. [CrossRef]

37. Hoffmann, M.R.; Martin, S.T.; Choi, W.; Bahnemann, D.W. Environmental applications of semiconductor photocatalysis. Chem. Rev. 1995, 95, 69-96. [CrossRef]

38. .'regan, B.; Grätzel, M. A low-cost, high-efficiency solar cell based on dye-sensitized colloidal $\mathrm{TiO}_{2}$ films. Nature. 1991, 353, 737.

39. Chen, X.; Mao, S.S. Titanium dioxide nanomaterial's: Synthesis, properties, modifications, and applications. Chem. Rev. 2007, 107, 2891-2959. [CrossRef]

40. Lee, K.H.; Song, S.W. One-step hydrothermal synthesis of meso-porous anatase $\mathrm{TiO}_{2}$ microsphere and interfacial control for enhanced lithium storage performance. ACS Appl. Mater. Interfaces 2011, 3, 3697-3703. [CrossRef]

41. Hao, B.; Yan, Y.; Wang, X.; Chen, G. Synthesis of anatase $\mathrm{TiO}_{2}$ nanosheets with enhanced pseudo capacitive contribution for fast lithium storage. ACS Appl. Mater. Interfaces 2013, 5, 6285-6291. [CrossRef]

42. Giannuzzi, R.; Manca, M.; De Marco, L.; Belviso, M.R.; Cannavale, A.; Sibillano, T.; Giannini, C.; Cozzoli, P.D.; Gigli, G. Ultrathin $\mathrm{TiO}_{2}$ (B) nano-rods with superior lithium-ion storage performance. ACS Appl. Mater. Interfaces 2014, 6, 1933-1943. [CrossRef] [PubMed]

43. Zhang, Y.; Wang, F.; Zhu, H.; Zhang, D.; Chen, J. Elongated $\mathrm{TiO}_{2}$ nanotubes directly grown on graphene nanosheets as an efficient material for supercapacitors and absorbents. Compos. Pt. A Appl. Sci. Manuf. 2017, 10, 297-305. [CrossRef]

44. Pawar, A.A.; Halivni, S.; Waiskopf, N.; Ben-Shahar, Y.; Soreni-Harari, M.; Bergbreiter, S.; Banin, U.; Magdassi, S. Rapid three-dimensional printing in water using semiconductor-metal hybrid nanoparticles as photoinitiators. Nano Lett. 2017, 17, 4497-4501. [CrossRef]

45. Waiskopf, N.; Ben-Shahar, Y.; Galchenko, M.; Carmel, I.; Moshitzky, G.; Soreq, H.; Banin, U. Photocatalytic reactive oxygen species formation by semiconductor-metal hybrid nanoparticles. Toward light-induced modulation of biological processes. Nano Lett. 2016, 16, 4266-4273. [CrossRef] [PubMed]

46. Mathias, F.; Tahir, M.N.; Tremel, W.; Zentel, R. Functionalization of $\mathrm{TiO}_{2}$ Nanoparticles with Semiconducting Polymers Containing a Photo cleavable Anchor Group and Separation via Irradiation Afterward. Macromol. Chem. Phys. 2014, 215, 604-613. [CrossRef]

47. Awazu, K.; Fujimaki, M.; Rockstuhl, C.; Tominaga, J.; Murakami, H.; Ohki, Y.; Yoshida, N.; Watanabe, T. A plasmonic photocatalyst consisting of silver nanoparticles embedded in titanium dioxide. J. Am. Chem. Soc. 2008, 130, 1676-1680. [CrossRef]

48. Glass, S.; Trinklein, B.; Abel, B.; Schulze, A. $\mathrm{TiO}_{2}$ as Photosensitizer and Photoinitiator for Synthesis of Photoactive $\mathrm{TiO}_{2}-\mathrm{PEGDA}$ Hydrogel without Organic Photoinitiator. Front. Chem. 2018, 6, 340. [CrossRef]

49. Nakayama, N.; Hayashi, T. Preparation and characterization of $\mathrm{TiO}_{2}-\mathrm{ZrO}_{2}$ and thiol-acrylate resin nanocomposites with high refractive index via UV-induced crosslinking polymerization. Compos. Pt. A Appl. Sci. Manuf. 2007, 38, 1996-2004. [CrossRef] 
50. Prasad, V.; Sekar, K.; Varghese, S.; Joseph, M.A. Enhancing Mode I and Mode II interlaminar fracture toughness of flax fiber reinforced epoxy composites with nano $\mathrm{TiO}_{2}$. Compos. Pt. A Appl. Sci. Manuf. 2019, 124, 105505. [CrossRef]

51. Thomas, S.P.; Thomas, S.; Bandyopadhyay, S. Mechanical, atomic force microscopy and focused ion beam studies of isotactic polystyrene/titanium dioxide composites. Compos. Pt. A Appl. Sci. Manuf. 2009, 40, 36-44. [CrossRef]

52. Hirakawa, T.; Kamat, P.V. Charge separation and catalytic activity of $\mathrm{Ag} @ \mathrm{TiO}_{2}$ core-shell composite clusters under UV-irradiation. J. Am. Chem. Soc. 2005, 127, 3928-3934. [CrossRef]

53. Yu, J.; Xiong, J.; Cheng, B.; Liu, S. Fabrication and characterization of Ag- $-\mathrm{TiO}_{2}$ multiphase nanocomposite thin films with enhanced photocatalytic activity. Appl. Catal. B Environ. 2005, 60, 211-221. [CrossRef]

54. Wang, S.; Han, Z.; Di, T.; Li, R.; Liu, S.; Cheng, Z. Preparation of pod-shaped $\mathrm{TiO}_{2}$ and $\mathrm{Ag@TiO} 2$ nano burst tubes and their photocatalytic activity. R. Soc. Open Sci. 2019, 6, 191019. [CrossRef]

55. Zhu, Y.; Zhang, L.; Gao, C.; Cao, L. The synthesis of nano-sized $\mathrm{TiO}_{2}$ powder using a sol-gel method with $\mathrm{TiCl}_{4}$ as a precursor. J. Mater. Sci. 2000, 35, 4049-4054. [CrossRef]

56. Ko, S.; Banerjee, C.K.; Sankar, J. Photochemical synthesis and photocatalytic activity in simulated solar light of nanosized Ag doped $\mathrm{TiO}_{2}$ nanoparticles composite. Compos. Pt. B Eng. 2011, 42, 579-583. [CrossRef]

57. Yugang, D.; Yuan, Z.; Yiping, T.; Dichen, L. Nano-TiO 2 -modified photosensitive resin for RP. Rapid Prototyp. J 2011, 17, 247-252. [CrossRef]

58. Zhang, Y.; Fu, F.; Li, Y.; Zhang, D.; Chen, Y. One-step synthesis of Ag@ $@ \mathrm{TiO}_{2}$ nanoparticles for enhanced photocatalytic performance. Nanomaterials 2018, 8, 1032. [CrossRef]

59. Duan, Y.; Zhang, M.; Wang, L.; Wang, F.; Yang, L.; Li, X.; Wang, C. Plasmonic Ag-TiO $2-X$ nanocomposites for the photocatalytic removal of NO under visible light with high selectivity: The role of oxygen vacancies. Appl. Catal. B Environ. 2017, 204, 67-77. [CrossRef]

60. Channei, D.; Inceesungvorn, B.; Wetchakun, N.; Ukritnukun, S.; Nattestad, A.; Chen, J.; Phanichphant, S. Photocatalytic degradation of methyl orange by $\mathrm{CeO}_{2}$ and $\mathrm{Fe}$-doped $\mathrm{CeO}_{2}$ films under visible light irradiation. Sci Rep. 2014, 4, 5757. [CrossRef]

61. Uddin, M.T.; Nicolas, Y.; Olivier, C.; Jaegermann, W.; Rockstroh, N.; Junge, H.; Toupance, T. Band alignment investigations of hetero-structure $\mathrm{NiO} / \mathrm{TiO}_{2}$ nanomaterial's used as efficient hetero-junction earth-abundant metal oxide photocatalysts for hydrogen production. Phys. Chem. Chem. Phys. 2017, 19, 19279-19288. [CrossRef]

62. Luttrell, T.; Halpegamage, S.; Tao, J.; Kramer, A.; Sutter, E.; Batzill, M. Why is anatase a better photocatalyst than rutile?-Model studies on epitaxial $\mathrm{TiO}_{2}$ films. Sci Rep. 2014, 4, 4043. [CrossRef]

63. Thomas, D.G. Transport characteristics of suspension: VIII. A note on the viscosity of Newtonian suspensions of uniform spherical particles. J. Colloid Sci. 1965, 20, 267-277. [CrossRef]

64. Li, Y.; Zhong, J.; Wu, L.; Weng, Z.; Zheng, L.; Peng, S.; Zhang, X. High performance POSS filled nanocomposites prepared via UV-curing based on 3D stereolithography printing. Compos. Pt. A Appl. Sci. Manuf. 2019, 117, 276-286. [CrossRef]

65. Weng, Z.; Zhou, Y.; Lin, W.; Senthil, T.; Wu, L. Structure-property relationship of nano enhanced stereolithography resin for desktop SLA 3D printer. Compos. Pt. A Appl. Sci. Manuf. 2016, 88, 234-242. [CrossRef]

66. Bahadur, S.; Henkin, A. Investigation of the ductility of rolled polymers. Polym. Eng. Sci. 1973, 13, 422-428. [CrossRef]

67. Markandan, K.; Lai, C.Q. Enhanced mechanical properties of 3D printed graphene-polymer composite lattices at very low graphene concentrations. Compos. Pt. A Appl. Sci. Manuf. 2020, 129, 105726. [CrossRef]

68. Amin, K.A. Reinforced materials based on chitosan, $\mathrm{TiO}_{2}$ and Ag composites. Polymers 2012, 4, 590-599. [CrossRef]

69. Harifi, T.; Montazer, M. Photo-, bio-, and magneto-active colored polyester fabric with hydrophobic/hydrophilic and enhanced mechanical properties through synthesis of $\mathrm{TiO}_{2} / \mathrm{Fe}_{3} \mathrm{O}_{4} / \mathrm{Ag}$ nanocomposite. Ind. Eng. Chem. Res. 2014, 53, 1119-1129. [CrossRef]

70. Senthil, T.; Divakaran, N.; Wang, J.; Wang, R.; Wu, L. Evolution of structural, electrical, and mechanical response of 3D robust network and conducting mechanically modified glass fabric-polyester composites with devisable 1D VGCNF. Compos. Sci. Technol. 2018, 163, 171-179. [CrossRef] 
71. Ma, P.C.; Kim, J.K.; Tang, B.Z. Effects of silane functionalization on the properties of carbon nanotube/epoxy nanocomposites. Compos. Sci. Technol. 2007, 67, 2965-2972. [CrossRef]

72. Liu, Y.; Zheng, S.; Nie, K. Epoxy nanocomposites with octa(propylglycidyl ether) polyhedral oligomeric silsesquioxane. Polymer 2005, 46, 12016-12025. [CrossRef]

73. Batmunkh, M.; Tanshen, M.R.; Nine, M.J.; Myekhlai, M.; Choi, H.; Chung, H.; Jeong, H. Thermal conductivity of $\mathrm{TiO}_{2}$ nanoparticles based aqueous nano-fluids with an addition of a modified silver particle. Ind. Eng. Chem. Res. 2014, 53, 8445-8451. [CrossRef]

74. Mubarak, S.; Dhamodharan, D.; Divakaran, N.; Kale, M.B.; Senthil, T.; Wu, L.; Wang, J. Enhanced Mechanical and Thermal Properties of Stereolithography 3D Printed Structures by the Effects of Incorporated Controllably Annealed Anatase $\mathrm{TiO}_{2}$ Nanoparticles. Nanomaterials 2020, 10, 79. [CrossRef]

75. Goldin, N.; Dodiuk, H.; Lewitus, D. Enhanced thermal conductivity of photopolymerizable composites using surface modified hexagonal boron nitride fillers. Compos. Sci. Technol. 2017, 152, 36-45. [CrossRef]

76. Sangermano, M.; Calvara, L.; Chiavazzo, E.; Ventola, L.; Asinari, P.; Mittal, V.; Rizzoli, R.; Ortolani, L.; Morandi, V. Enhancement of electrical and thermal conductivity of Su-8 photocrosslinked coatings containing graphene. Prog. Org. Coat. 2015, 86, 143-146. [CrossRef]

77. Sangermano, M.; Razza, N.; Graham, G.; Barandiaran, I.; Kortaberria, G. Electrically insulating polymeric nanocomposites with enhanced thermal conductivity by visible-light curing of epoxy-boron nitride nanotube formulations. Polym. Int. 2017, 66, 1935-1939. [CrossRef]

78. Hung, W.I.; Lin, Y.H.; Wu, P.S.; Chang, K.C.; Peng, C.W.; Lai, M.C.; Yeh, J.M. Preparation and thermal properties of UV-curable polyacrylate-gold nanocomposite foams. J. Mater. Chem. 2012, 22, 21654-21661. [CrossRef]

79. Decker, C.; Moussa, K. Real-time kinetic study of laser-induced polymerization. Macromolecules 1989, 22, 4455-4462. [CrossRef]

80. Avens, H.J.; Bowman, C.N. Mechanism of cyclic dye regeneration during eosinsensitized photoinitiation in the presence of polymerization inhibitors. J. Polym. Sci. Pt. A Polym. Chem. 2009, 47, 6083-6094. [CrossRef]

81. Decker, C.; Moussa, K. A new method for monitoring ultra-fast photopolymerizations by real-time infra-red (RTIR) spectroscopy. Die Makromol. Chem. Macromol. Chem. Phys. 1988, 189, 2381-2394. [CrossRef]

82. Zhang, D.; Yang, J.; Bao, S.; Wu, Q.; Wang, Q. Semiconductor nanoparticle-based hydrogels prepared via self-initiated polymerization under sunlight, even visible light. Sci. Rep. 2013, 3, 1399. [CrossRef]

83. Ni, X.; Ye, J.; Dong, C. Kinetics studies of methyl methacrylate photopolymerization initiated by titanium dioxide semiconductor nanoparticles. J. Photochem. Photobiol. A Chem. 2006, 181, 19-27. [CrossRef]

84. Sangermano, M.; Marino, F.; Reuel, N.; Strano, M.S. Semiconducting Single-Walled Carbon Nanotubes as Radical Photoinitiators. Macromol. Chem. Phys. 2011, 212, 1469-1473. [CrossRef]

85. Dadashi-Silab, S.; Yar, Y.; Acar, H.Y.; Yagci, Y. Magnetic iron oxide nanoparticles as long wavelength photoinitiators for free radical polymerization. Polym. Chem. 2015, 6, 1918-1922. [CrossRef]

86. Heller, D.A.; Jin, H.; Martinez, B.M.; Patel, D.; Miller, B.M.; Yeung, T.K.; Jena, P.V.; Höbartner, C.; Ha, T.; Silverman, S.K.; et al. Multimodal optical sensing and analyte specificity using single-walled carbon nanotubes. Nat. Nanotechnol. 2009, 4, 114. [CrossRef]

(C) 2020 by the authors. Licensee MDPI, Basel, Switzerland. This article is an open access article distributed under the terms and conditions of the Creative Commons Attribution (CC BY) license (http://creativecommons.org/licenses/by/4.0/). 